\title{
The Genera of Fungi-G3: Aleurocystis, Blastacervulus, Clypeophysalospora, Licrostroma, Neohendersonia and Spumatoria
}

\author{
Alejandra Giraldo ${ }^{1,2}$ • Pedro W. Crous ${ }^{1,2,3,4}$ - René K. Schumacher ${ }^{5}$. \\ Ratchadawan Cheewangkoon ${ }^{4} \cdot$ Masoomeh Ghobad-Nejhad $^{6} \cdot$ Ewald Langer $^{7}$
}

Received: 10 October 2016 / Revised: 1 January 2017 / Accepted: 3 January 2017 / Published online: 30 January 2017

(C) The Author(s) 2017. This article is published with open access at Springerlink.com

\begin{abstract}
The current paper represents the third contribution in the Genera of Fungi series, linking the type species of fungal genera to their morphology and DNA sequence data, and, where possible, ecology. In this issue, we have focused on six genera, including macro- and microfungi, four of which the type species is epitypified. In addition, two new families within Pleosporales and Xylariales are proposed to accommodate two of them. The genera treated here include: Aleurocystis (Aleurocystis hakgallae; incertae sedis, Agaricales), Blastacervulus (Blastacervulus eucalypti; Asterinaceae, Asterinales), Clypeophysalospora (Clypeophysalospora latitans; Clypeophysalosporaceae, Xylariales), Licrostroma (Licrostroma subgiganteum;
\end{abstract}

Section Editor: Kevin Hyde and Marc Stadler

This article is part of the "Special Issue in honour of the 70th birthday of Dr. Eric McKenzie”.

Pedro W. Crous

p.crous@cbs.knaw.nl

1 Westerdijk Fungal Biodiversity Centre, Uppsalalaan 8, 3584 CT Utrecht, The Netherlands

2 Department of Microbiology and Plant Pathology, Forestry and Agricultural Biotechnology Institute (FABI), University of Pretoria, P. Bag X20, 0028 Pretoria, South Africa

3 Microbiology, Department of Biology, Utrecht University, Padualaan 8, 3584 CH Utrecht, The Netherlands

4 Department of Entomology and Plant Pathology, Faculty of Agriculture, Chiang Mai University, Chiang Mai 50200, Thailand

5 Hölderlinstraße 25, Fürstenwalde/Spree 15517, Germany

6 Department of Biotechnology, Iranian Research Organization for Science and Technology (IROST), P.O. Box 3353-5111, Tehran 3353136846, Iran

7 Department of Ecology, University of Kassel, Heinrich-Plett-Str. 40, D-34132 Kassel, Germany
Peniophoraceae, Russulales), Neohendersonia (Neohendersonia kickxii; Neohendersoniaceae, Pleosporales) and Spumatoria (Spumatoria longicollis; Ophiostomataceae, Ophiostomatales). Authors interested in contributing accounts of individual genera to larger multi-authored papers should contact the associate editors listed on the List of Protected Generic Names for Fungi.

Keywords DNA barcodes $\cdot$ Fungal systematics $\cdot$ ITS $\cdot$ LSU $\cdot$ Typification

\section{Introduction}

The Genera of Fungi project (http://www.GeneraOfFungi.org; Crous et al. 2014a) aims to revise the generic names of fungi that are currently accepted (Kirk et al. 2013) and anticipated to obtain 'protected status' at the next International Botanical Congress (IBC XIX) in China in 2017. Because the majority of fungal genera were described before the DNA era, their type species need to be recollected, epi- or neotypes designated and assigned an MBT number to ensure traceability of the nomenclatural act (Robert et al. 2013), and sequence data obtained to resolve their true higher order phylogeny. Furthermore, to move to a single nomenclature for fungi (Crous et al. 2015a), their sexual-asexual links also need to be confirmed.

\section{Materials and methods}

Isolates

Several genera were re-described based on cultures obtained from the Westerdijk Fungal Biodiversity Centre in Utrecht, 
The Netherlands (formerly known as CBS-KNAW) and the working collection of P.W. Crous (CPC), housed at the CBS. For fresh collections, leaves and twigs were placed in damp chambers and incubated at room temperature for 1-2 days. Single conidial or ascospore colonies were established from sporulating conidiomata or ascomata in Petri dishes containing $2 \%$ malt extract agar (MEA), as described previously (Crous et al. 1991). In the case of the dung samples, small pieces were placed on moist sterile filter paper on the lid of Petri dishes containing MEA, until the spores were shot onto the surface of the agar. After 1-2 days, single spores were picked up and transferred to fresh MEA plates. Colonies were sub-cultured onto $2 \%$ potato dextrose agar (PDA), oatmeal agar (OA), MEA (Crous et al. 2009c), autoclaved pine needles on $2 \%$ tap water agar (PNA) (Smith et al. 1996) and incubated at $25{ }^{\circ} \mathrm{C}$ under continuous near-ultraviolet light to promote sporulation. Reference strains and specimens are maintained at the CBS and CPC.

\section{DNA isolation, amplification and analyses}

Genomic DNA was extracted from fungal colonies growing on MEA using the UltraClean ${ }^{\mathrm{TM}}$ Microbial DNA Isolation Kit (MO BIO Laboratories, Inc., Solana Beach, CA, USA), according to the manufacturer's protocol. The primers V9G (de Hoog and Gerrits van den Ende 1998) or ITS5 (White et al. 1990) and LR5 (Vilgalys and Hester 1990) were used to amplify part (ITS) of the nuclear rDNA operon spanning the $3^{\prime}$ end of the 18S nrRNA gene, the first internal transcribed spacer (ITS1), the 5.8S nrRNA gene, the second ITS region (ITS2) and approximately 900 bp of the $5^{\prime}$ end of the $28 \mathrm{~S}$ nrRNA gene. The primers ITS4 (White et al. 1990) and LROR (Vilgalys and Hester 1990) were used as internal sequence primers to ensure good quality sequences over the entire length of the amplicon. Amplification conditions followed Cheewangkoon et al. (2008). The program SeqMan v.7.0.0 (DNASTAR, Madison, WI, USA) was used to obtain consensus sequences of each isolate. BLAST searches using ITS and LSU sequences were performed for each isolate and the closest matches were retrieved from GenBank and included in the phylogenetic analysis. The multiple sequence alignments and subsequent phylogenetic analyses of the LSU data were carried out using ClustalW and maximum likelihood (ML), respectively, under MEGA v.6.06 (Tamura et al. 2013). Sequence data were deposited in GenBank (Table 1) and the alignments and trees in TreeBASE (http://www.treebase.org). In addition, 186 LSU sequences retrieved from GenBank were included in the phylogenetic analyses (Table 2).

\section{Morphology}

Slide preparations were mounted in lactic acid or Shear's mounting fluid from colonies sporulating on the media previously mentioned. Sections of fruiting bodies were made by hand. Observations were made with a Zeiss V20 Discovery stereo-microscope (Zeiss, Oberkochen, Germany) and with a Zeiss Axio Imager 2 light microscope using differential interference contrast (DIC) illumination and a Nikon DS-Ri2 camera and software. Colony characters and pigment production were noted after 1 month of growth on MEA and OA (Crous et al. 2009c) incubated at $25{ }^{\circ} \mathrm{C}$. Colony colours (surface and reverse) were rated according to the colour charts of Rayner (1970). Taxonomic novelties and new typifications were deposited in MycoBank (http://www. MycoBank.org; Crous et al. 2004).

\section{Results}

\section{Phylogeny}

The LSU alignment was used to resolve the generic placement of strains (Figs. 1, 2, 3 and 4) and the ITS (not shown) was used for species identification. According to the BLAST search results using the LSU and ITS sequences of Blastacervulus eucalypti, it was closely related with members of Asterinales (Dothideomycetes). Thus, the currently accepted members of this order as well as other orders from Dothideomycetes were included in our analysis. The final alignment contained 62 taxa including the outgroup, and 862 characters including alignment gaps; 338 of these were phylogenetically informative, 40 were variable and phylogenetically-uninformative, and 454 were constant. Tamura-Nei with Gamma distribution (TN93 + G) was used as the best-fit nucleotide substitution model for the ML analysis. The single isolate of Blastacervulus eucalypti was clustered in a wellsupported clade (99\% BS) together with Aulographina eucalypti and species of Alysidiella, being distinct from those species. This clade was phylogenetically related [98\% bootstrap support (BS) value] with other members of Asterinaceae (Guatimosim et al. 2015) and all of them were grouped within the Asterinales clade (Fig. 1).

The BLAST search result using the LSU and ITS regions of the five isolates of Clypeophysalospora latitans showed them to be the closest taxa members of Xylariales and, therefore, representatives of different families if this order were added to the alignment. The final alignment included 42 taxa, including the outgroup sequences. The alignment comprised $794 \mathrm{bp}$, including alignment gaps; 179 of these were phylogenetically informative, 195 were variable and phylogenetically-uninformative, and 598 were conserved. Kimura 2-parameter with Gamma distribution $(\mathrm{K} 2+\mathrm{G})$ was used as the bestfit nucleotide substitution model for the ML analysis. The five isolates of Clypeophysalospora were placed 
Table 1 Details of the strains included in this study

\begin{tabular}{|c|c|c|c|c|c|c|}
\hline \multirow[t]{2}{*}{ Species name } & \multirow[t]{2}{*}{$\begin{array}{l}\text { Strain accession } \\
\text { number }^{\mathrm{a}}\end{array}$} & \multirow[t]{2}{*}{ Locality } & \multirow[t]{2}{*}{ Substrate } & \multirow[t]{2}{*}{ Collector(s) } & \multicolumn{2}{|c|}{$\begin{array}{l}\text { GenBank } \\
\text { accession numbers }\end{array}$} \\
\hline & & & & & ITS & LSU \\
\hline $\begin{array}{l}\text { Aleurocystis } \\
\text { hakgallae }\end{array}$ & CFMR & USA: Hawaii & Sapindus saponaria & $\begin{array}{l}\text { R.L.G. } \\
\text { Gilbertson }\end{array}$ & KX358899 & KX358900 \\
\hline $\begin{array}{l}\text { Blastacervulus } \\
\text { eucalypti }\end{array}$ & $\begin{array}{l}\text { CBS } 124759, \\
\text { CPC 13956, } \\
\text { ex-epitype }\end{array}$ & $\begin{array}{l}\text { Australia: } \\
\quad \text { Mullion Creek }\end{array}$ & $\begin{array}{l}\text { Eucalyptus robertsonii } \\
\text { subsp. hemisphaerica, } \\
\text { living leaves }\end{array}$ & $\begin{array}{l}\text { B.A. } \\
\text { Summerell }\end{array}$ & GQ303271 & GQ303302 \\
\hline \multirow[t]{5}{*}{$\begin{array}{l}\text { Clypeophysalospora } \\
\text { latitans }\end{array}$} & $\begin{array}{l}\text { CBS } 141463, \\
\text { CPC 14930, } \\
\text { ex-epitype }\end{array}$ & $\begin{array}{l}\text { Portugal: Algarve region, } \\
\text { Faro }\end{array}$ & $\begin{array}{l}\text { Eucalyptus sp., } \\
\text { leaves }\end{array}$ & P.W. Crous & KX820250 & KX820261 \\
\hline & СРC 14931 & $\begin{array}{l}\text { Portugal: Algarve region, } \\
\text { Faro }\end{array}$ & Eucalyptus sp., leaves & P.W. Crous & KX820251 & KX820262 \\
\hline & СРC 14932 & $\begin{array}{l}\text { Portugal: Algarve region, } \\
\text { Faro }\end{array}$ & Eucalyptus sp., leaves & P.W. Crous & KX820252 & KX820263 \\
\hline & СРC 19661 & $\begin{array}{l}\text { South Africa: Stellenbosch } \\
\text { mountain }\end{array}$ & Eucalyptus sp., leaves & P.W. Crous & KX820253 & KX820264 \\
\hline & СРC 27352 & France: Corsica, Porto & Eucalyptus sp., leaves & A. van Iperen & KX820254 & KX820265 \\
\hline $\begin{array}{l}\text { Licrostroma } \\
\text { subgiganteum }\end{array}$ & CFMR & USA: Maine & Acer rubrum, dead snag & R.J. Pinette & KX358901 & KX358902 \\
\hline \multirow[t]{4}{*}{$\begin{array}{l}\text { Neohendersonia } \\
\text { kickxii }\end{array}$} & $\begin{array}{c}\text { CBS } 112403, \\
\text { ex-epitype }\end{array}$ & Italy: Pian di Novello & $\begin{array}{l}\text { Fagus sylvatica, } \\
\text { bark of twigs }\end{array}$ & R. Danti & KX820255 & KX820266 \\
\hline & CBS 114276 & Sweden: Uppland & Fagus sp. & K. \& L. Holm & KX820256 & KX820267 \\
\hline & CBS 122938 & $\begin{array}{l}\text { Austria: Carinthia, } \\
\text { Sankt Margareten im } \\
\text { Rosental }\end{array}$ & Fagus sylvatica & W. Jaklitsch & KX820257 & KX820268 \\
\hline & CBS 122941 & $\begin{array}{l}\text { Austria: Grieskirchen, } \\
\text { Natternbach }\end{array}$ & Fagus sylvatica & H. Voglmayr & KX820258 & KX820269 \\
\hline Neohendersonia sp. & СРC 24865 & Germany & Fagus sylvatica, twigs & $\begin{array}{l}\text { R.K. } \\
\text { Schumacher }\end{array}$ & KX820259 & KX820270 \\
\hline $\begin{array}{l}\text { Spumatoria } \\
\text { longicollis }\end{array}$ & $\begin{array}{l}\text { CBS } 141464, \\
\text { CPC 30521, } \\
\text { ex-epitype }\end{array}$ & $\begin{array}{l}\text { Netherlands: } \\
\text { near Oostvoorne }\end{array}$ & Cow’s (Galloway) dung & J. van der Lee & KX820260 & KX820271 \\
\hline
\end{tabular}

${ }^{a}$ CBS: Westerdijk Fungal Biodiversity Centre Utrecht, The Netherlands; CFMR: Center for Forest Mycology Research, Madison, USA; CPC: Collection Pedro Crous, housed at CBS

${ }^{\mathrm{b}}$ ITS: internal transcribed spacers and intervening 5.8S nrDNA; LSU: partial $28 \mathrm{~S}$ nrDNA. Sequences newly generated in this study are indicated in bold

in a fully supported monophyletic clade (100\% BS), phylogenetically related with the type species of Plectosphaera eucalypti, Neophysalospora eucalypti and species of Bagadiella (Fig. 2). The clade containing these genera represents a new lineage within the Xylariales and, therefore, a new family is proposed below to accommodate them.

The analysis of the LSU and ITS sequences from the five isolates of Neohendersonia kickxii using BLAST searches showed them to be the closest matches to members of Pleosporales (Dothideomycetes) but without resolution at the family level. The manually adjusted LSU alignment was constructed with representatives of different families of that order and contained 75 sequences (including the outgroup sequences) and 809 characters, including alignment gaps. In total, $224 \mathrm{bp}$ were phylogenetically informative, $252 \mathrm{bp}$ were variable and phylogenetically-uninformative, and 548 bp were constant. The Kimura 2-parameter model with Gamma distribution and invariable sites $(\mathrm{K} 2+\mathrm{G}+\mathrm{I})$ was used as the best-fit nucleotide substitution model for the ML analysis. In this analysis, the isolates of Neohendersonia kickxii clustered in a strongly supported monophyletic clade (100\% BS), representing a novel family lineage within Pleosporales (Fig. 3).

The BLAST search result using the LSU, ITS and $\beta$ tubulin regions of Spumatoria longicollis showed them to be the closest matches to members of Ophiostomataceae (Ophiostomatales) and, therefore, they were included in the phylogenetic tree (Fig. 4). The final alignment included 21 taxa, including the outgroup, and 689 characters, including alignment gaps; 69 of these were phylogenetically informative, 91 were variable and phylogenetically-uninformative, and 598 were constant. Tamura-Nei with Gamma distribution and invariable sites $(\mathrm{TN} 93+\mathrm{G}+\mathrm{I})$ was used as the 
Table 2 Taxa used in the phylogenetic analyses, along with their GenBank accession numbers

\begin{tabular}{|c|c|c|c|c|}
\hline Species name & $\begin{array}{l}\text { Strain } \\
\text { accession } \\
\text { number }^{\mathrm{a}}\end{array}$ & Origin & $\begin{array}{l}\text { GenBank } \\
\text { accession } \\
\text { number }(\mathrm{LSU})^{\mathrm{b}}\end{array}$ & Reference \\
\hline Medicopsis romeroi & CBS 128765 & $\begin{array}{l}\text { Kuwait, human } \\
\text { subcutaneous cyst }\end{array}$ & KF015621 & Ahmed et al. (2014) \\
\hline $\begin{array}{l}\text { Aliquandostipite } \\
\text { khaoyaiensis }\end{array}$ & CBS 118232 & $\begin{array}{l}\text { Thailand, decaying } \\
\text { branch }\end{array}$ & GU301796 & Schoch et al. (2009a) \\
\hline Alysidiella eucalypti & CBS 120122 & $\begin{array}{l}\text { Uruguay, Eucalyptus } \\
\text { dunnii }\end{array}$ & DQ885893 & Crous et al. (2006a) \\
\hline Alysidiella kleinziense & CBS 120138 & $\begin{array}{l}\text { South Africa, } \\
\quad \text { Eucalyptus sp. }\end{array}$ & EF110616 & Crous et al. (2007b) \\
\hline Alysidiella parasitica & CBS 120088 & $\begin{array}{l}\text { South Africa, } \\
\text { Eucalyptus sp. }\end{array}$ & DQ923525 & $\begin{array}{l}\text { Summerell et al. } \\
\text { (2006) }\end{array}$ \\
\hline Alysidiella suttonii & CBS 124780 & $\begin{array}{l}\text { Cyprus, Eucalyptus } \\
\text { sp. }\end{array}$ & HM628777 & $\begin{array}{l}\text { Cheewangkoon et al. } \\
\text { (2012) }\end{array}$ \\
\hline Apiospora montagnei & ICMP 6967 & Unknown & DQ414530 & Tang et al. (2007) \\
\hline Apiospora sinensis & Unknown & Unknown & DQ810215 & Unpublished \\
\hline Apiosporina collinsii & CBS 118973 & $\begin{array}{l}\text { Canada, Amelanchier } \\
\quad \text { alnifolia }\end{array}$ & GU301798 & Schoch et al. (2009a) \\
\hline Apiosporina morbosa & Unknown & USA, Prunus sp. & EF114694 & Winton et al. (2007) \\
\hline $\begin{array}{l}\text { Arthrinium } \\
\quad \text { phaeospermum }\end{array}$ & $\begin{array}{l}\text { HKUCC } \\
3395\end{array}$ & Unknown & AY083832 & Unpublished \\
\hline $\begin{array}{l}\text { Arthrinium } \\
\quad \text { saccharicola }\end{array}$ & CBS 191.73 & Netherlands, air & KF144966 & $\begin{array}{l}\text { Crous and } \\
\text { Groenewald } \\
(2013)\end{array}$ \\
\hline $\begin{array}{l}\text { Ascocylindrica } \\
\quad \text { marina }\end{array}$ & MD6012* & $\begin{array}{l}\text { Saudi Arabia, } \\
\text { Unknown host }\end{array}$ & KT252906 & Unpublished \\
\hline $\begin{array}{l}\text { Ascocylindrica } \\
\quad \text { marina }\end{array}$ & MD6011* & $\begin{array}{l}\text { Saudi Arabia, decayed } \\
\text { wood at a sandy } \\
\text { beach }\end{array}$ & KT252905 & Unpublished \\
\hline Asterina chrysophylli & VIC 42823 & Brazil, Cerrado biome & KP143738 & $\begin{array}{l}\text { Guatimosim et al. } \\
\text { (2015) }\end{array}$ \\
\hline Asterina melastomatis & VIC 42822 & $\begin{array}{l}\text { Brazil, Atlantic } \\
\text { rainforest }\end{array}$ & KP143739 & $\begin{array}{l}\text { Guatimosim et al. } \\
\text { (2015) }\end{array}$ \\
\hline $\begin{array}{l}\text { Asterotexis } \\
\quad \text { cucurbitacearum }\end{array}$ & VIC 42814 & $\begin{array}{l}\text { Brazil, conserved area } \\
\text { of Atlantic } \\
\text { rainforest }\end{array}$ & KP143734 & $\begin{array}{l}\text { Guatimosim et al. } \\
\text { (2015) }\end{array}$ \\
\hline $\begin{array}{l}\text { Asterotexis } \\
\quad \text { cucurbitacearum }\end{array}$ & $\begin{array}{l}\text { PMA } \\
\qquad \begin{array}{l}\text { M-01412- } \\
24 *\end{array}\end{array}$ & $\begin{array}{l}\text { Panama, Sechium } \\
\text { edule }\end{array}$ & HQ610510 & Unpublished \\
\hline $\begin{array}{l}\text { Aulographina } \\
\text { eucalypti }\end{array}$ & СРC 12986 & $\begin{array}{l}\text { Australia, Eucalyptus } \\
\text { cloeziana }\end{array}$ & HM535600 & $\begin{array}{l}\text { Cheewangkoon et al. } \\
\text { (2012) }\end{array}$ \\
\hline Bagadiella koalae & СРC 17682 & $\begin{array}{l}\text { Australia, Eucalyptus } \\
\text { globulus }\end{array}$ & JF951162 & Crous et al. (2011) \\
\hline Bagadiella lunata & CBS 124762 & $\begin{array}{l}\text { Australia, Eucalyptus } \\
\text { globulus }\end{array}$ & GQ303300 & $\begin{array}{l}\text { Cheewangkoon et al. } \\
\text { (2009) }\end{array}$ \\
\hline Bagadiella victoriae & СРC 17688 & $\begin{array}{l}\text { Australia, Eucalyptus } \\
\text { sp. }\end{array}$ & JF951161 & Crous et al. (2011) \\
\hline $\begin{array}{l}\text { Bambusicola } \\
\text { bambusae }\end{array}$ & $\begin{array}{r}\text { MFLUCC } \\
11-0614\end{array}$ & Thailand, Bamboo & JX442035 & Dai et al. (2015) \\
\hline Bambusicola loculata & $\begin{array}{l}\text { MFLU } \\
\quad 15-0056\end{array}$ & Thailand, Bamboo & KP761729 & Dai et al. (2015) \\
\hline $\begin{array}{l}\text { Bambusicola } \\
\text { massarinia }\end{array}$ & $\begin{array}{r}\text { MFLUCC } \\
11-0389\end{array}$ & Thailand, Bamboo & JX442037 & Dai et al. (2015) \\
\hline Batistinula gallesiae & VIC 42514 & $\begin{array}{l}\text { Brazil, Atlantic } \\
\text { rainforest }\end{array}$ & KP143736 & $\begin{array}{l}\text { Guatimosim et al. } \\
\text { (2015) }\end{array}$ \\
\hline Batistinula gallesiae & Unknown & $\begin{array}{l}\text { Brazil, Caesalpinia } \\
\quad \text { echinata }\end{array}$ & KM111255 & Unpublished \\
\hline $\begin{array}{l}\text { Beltrania } \\
\quad \text { pseudorhombica }\end{array}$ & CBS 138003 & $\begin{array}{l}\text { China, Pinus } \\
\text { tabulaeformis }\end{array}$ & KJ869215 & Crous et al. (2014b) \\
\hline
\end{tabular}


Table 2 (continued)

\begin{tabular}{|c|c|c|c|c|}
\hline Species name & $\begin{array}{l}\text { Strain } \\
\text { accession }^{\text {number }}\end{array}$ & Origin & $\begin{array}{l}\text { GenBank } \\
\text { accession } \\
\text { number }(\mathrm{LSU})^{\mathrm{b}}\end{array}$ & Reference \\
\hline $\begin{array}{l}\text { Beltraniella } \\
\text { endiandrae }\end{array}$ & CBS 137976 & $\begin{array}{l}\text { Australia, Endiandra } \\
\quad \text { introrsa }\end{array}$ & KJ869185 & Crous et al. (2014b) \\
\hline $\begin{array}{c}\text { Beltraniopsis } \\
\text { neolitseae }\end{array}$ & CBS 137974 & $\begin{array}{l}\text { Australia, Neolitsea } \\
\text { australiensis }\end{array}$ & KJ869183 & Crous et al. (2014b) \\
\hline $\begin{array}{l}\text { Botryosphaeria } \\
\text { dothidea }\end{array}$ & CBS 115476 & $\begin{array}{l}\text { Switzerland, Prunus } \\
\text { sp. }\end{array}$ & DQ377852 & Crous et al. (2006b) \\
\hline Capnodium coffeae & CBS 147.52 & Zaire, Coffea robusta & DQ247800 & Schoch et al. (2006a) \\
\hline Capnodium salicinum & CBS 131.34 & $\begin{array}{l}\text { Indonesia, Bursaria } \\
\text { spinosa }\end{array}$ & DQ678050 & Schoch et al. (2006b) \\
\hline $\begin{array}{l}\text { Ceratocystiopsis } \\
\quad \text { minima }\end{array}$ & CMW162 & $\begin{array}{l}\text { USA, Pinus } \\
\text { banksiana }\end{array}$ & DQ294361 & Zipfel et al. (2006) \\
\hline $\begin{array}{l}\text { Ceratocystiopsis } \\
\quad \text { minuta-bicolor }\end{array}$ & CMW1018 & $\begin{array}{l}\text { Unknown, Ips gallery } \\
\text { in Pinus }\end{array}$ & DQ294359 & Zipfel et al. (2006) \\
\hline $\begin{array}{l}\text { Ceratocystiopsis } \\
\quad \text { rollhanseniana }\end{array}$ & CW13791* & $\begin{array}{l}\text { Norway, beetle } \\
\text { galleries in Pinus } \\
\text { sylvestris }\end{array}$ & DQ294362 & Zipfel et al. (2006) \\
\hline $\begin{array}{l}\text { Clypeosphaeria } \\
\text { uniseptata }\end{array}$ & $\begin{array}{c}\text { HKUCC } \\
6349\end{array}$ & Unknown & AY083830 & Unpublished \\
\hline Cochliobolus sativus & $\begin{array}{l}\text { DAOM } \\
226212\end{array}$ & $\begin{array}{l}\text { Unknown, from } \\
\text { Poaceae }\end{array}$ & DQ678045 & Schoch et al. (2006b) \\
\hline $\begin{array}{c}\text { Corynespora } \\
\text { cassiicola }\end{array}$ & CBS 100822 & $\begin{array}{l}\text { Netherlands, } \\
\text { Saintpaulia } \\
\text { ionantha }\end{array}$ & GU301808 & Schoch et al. (2009a) \\
\hline Corynespora smithii & CABI 5649b & Unknown & GU323201 & Schoch et al. (2009a) \\
\hline Corynespora torulosa & CBS 136419 & $\begin{array}{l}\text { Mexico, Musa } \\
\text { acuminata }\end{array}$ & KF777207 & Crous et al. (2013) \\
\hline $\begin{array}{l}\text { Cryptosphaeria } \\
\text { eunomia }\end{array}$ & CBS 216.97 & $\begin{array}{l}\text { New Zealand, rabbit } \\
\text { dung }\end{array}$ & AY083826 & Unpublished \\
\hline $\begin{array}{l}\text { Cucurbitaria } \\
\text { berberidis }\end{array}$ & CBS 394.84 & $\begin{array}{l}\text { Netherlands, Berberis } \\
\text { julianae }\end{array}$ & GQ387605 & $\begin{array}{l}\text { de Gruyter et al. } \\
\text { (2010) }\end{array}$ \\
\hline $\begin{array}{c}\text { Cucurbitaria } \\
\text { berberidis }\end{array}$ & CBS 130007 & $\begin{array}{l}\text { Austria, Berberis } \\
\text { vulgaris }\end{array}$ & KC506793 & Unpublished \\
\hline Diaporthe padi & AR3419 & Austria, Prunus padus & AF408354 & $\begin{array}{l}\text { Castlebury et al. } \\
\text { (2002) }\end{array}$ \\
\hline Diaporthe perjuncta & AR3461 & Austria, Ulmus glabra & AF408356 & $\begin{array}{l}\text { Castlebury et al. } \\
\text { (2002) }\end{array}$ \\
\hline Diplodia mutila & CBS 431.82 & $\begin{array}{l}\text { Netherlands, Fraxinus } \\
\quad \text { excelsior }\end{array}$ & DQ377863 & Crous et al. (2006b) \\
\hline $\begin{array}{l}\text { Dissoconium } \\
\text { aciculare }\end{array}$ & CBS 204.89 & $\begin{array}{l}\text { Germany, Astragalus } \\
\text { sp. }\end{array}$ & GU214419 & Crous et al. (2009a) \\
\hline $\begin{array}{l}\text { Dissoconium } \\
\text { commune }\end{array}$ & CBS 110747 & $\begin{array}{l}\text { South Africa, } \\
\text { Eucalyptus nitens }\end{array}$ & GQ852589 & Crous et al. (2009b) \\
\hline Dissoconium dekkeri & CBS 111282 & $\begin{array}{l}\text { Zambia, Eucalyptus } \\
\text { globulus }\end{array}$ & GU214425 & Crous et al. (2009a) \\
\hline Eutypa sp. & HKUCC 337 & Unknown & AY083825 & Unpublished \\
\hline Gibbera conferta & CBS 191.53 & $\begin{array}{l}\text { Switzerland, } \\
\text { Vaccinium } \\
\text { uliginosum }\end{array}$ & GU301814 & Schoch et al. (2009a) \\
\hline Gloniopsis arciformis & $\begin{array}{l}\text { GKM } \\
\text { L166A }\end{array}$ & Unknown & GU323211 & Schoch et al. (2009a) \\
\hline $\begin{array}{l}\text { Glonium } \\
\quad \text { circumserpens }\end{array}$ & CBS 123342 & $\begin{array}{l}\text { Tasmania, } \\
\text { decorticated } \\
\text { hardwood }\end{array}$ & FJ161208 & Boehm et al. (2009) \\
\hline $\begin{array}{l}\text { Glonium } \\
\quad \text { circumserpens }\end{array}$ & CBS 123343 & $\begin{array}{l}\text { Tasmania, saxicolous } \\
\text { on limestone }\end{array}$ & FJ161200 & Boehm et al. (2009) \\
\hline \multirow[t]{2}{*}{ Helicomyces roseus } & CBS 283.51 & $\begin{array}{l}\text { Switzerland, } \\
\text { submerged bark }\end{array}$ & AY856881 & $\begin{array}{l}\text { Tsui and Berbee } \\
\quad(2006)\end{array}$ \\
\hline & & Japan, dead wood & AB807521 & Tanaka et al. (2015) \\
\hline
\end{tabular}


Table 2 (continued)

\begin{tabular}{|c|c|c|c|c|}
\hline Species name & $\begin{array}{l}\text { Strain } \\
\text { accession } \\
\text { number }^{\mathrm{a}}\end{array}$ & Origin & $\begin{array}{l}\text { GenBank } \\
\text { accession } \\
\text { number }(\mathrm{LSU})^{\mathrm{b}}\end{array}$ & Reference \\
\hline $\begin{array}{l}\text { Helminthosporium } \\
\text { dalbergiae }\end{array}$ & $\begin{array}{l}\text { HHUF } \\
27971\end{array}$ & & & \\
\hline $\begin{array}{l}\text { Helminthosporium } \\
\text { magnisporum }\end{array}$ & $\begin{array}{l}\text { HHUF } \\
27968\end{array}$ & Japan, dead wood & AB807522 & Tanaka et al. (2015) \\
\hline $\begin{array}{l}\text { Helminthosporium } \\
\text { massarinum }\end{array}$ & $\begin{array}{l}\text { HHUF } \\
27573\end{array}$ & $\begin{array}{l}\text { Japan, Berchemia } \\
\quad \text { racemosa }\end{array}$ & AB807523 & Tanaka et al. (2015) \\
\hline $\begin{array}{l}\text { Helminthosporium } \\
\text { velutinum }\end{array}$ & $\begin{array}{l}\text { HHUF } \\
\quad 30140\end{array}$ & $\begin{array}{l}\text { Japan, submerged } \\
\text { woody plant }\end{array}$ & AB807529 & Tanaka et al. (2015) \\
\hline $\begin{array}{l}\text { Hysterium } \\
\text { angustatum }\end{array}$ & CBS 123334 & USA, Pinus rigida & FJ161207 & Boehm et al. (2009) \\
\hline $\begin{array}{l}\text { Hysteropatella } \\
\text { clavispora }\end{array}$ & BCC 28877 & Unknown & GU371829 & Schoch et al. (2009a) \\
\hline Idriella lunata & CBS 204.56 & $\begin{array}{l}\text { USA, Fragaria } \\
\text { chiloensis var. } \\
\text { ananassa }\end{array}$ & KP858981 & $\begin{array}{l}\text { Hernández-Restrepo } \\
\text { et al. (2016) }\end{array}$ \\
\hline Idriella lunata & CBS 177.57 & USA, unknown host & KP858980 & $\begin{array}{l}\text { Hernández-Restrepo } \\
\text { et al. (2016) }\end{array}$ \\
\hline Inocyclus angularis & VIC 39749 & $\begin{array}{l}\text { Brazil, Atlantic } \\
\text { rainforest }\end{array}$ & KP143733 & $\begin{array}{l}\text { Guatimosim et al. } \\
\text { (2015) }\end{array}$ \\
\hline Inocyclus angularis & VIC 39747 & $\begin{array}{l}\text { Brazil, epiphytic on } \\
\text { garden tree }\end{array}$ & KP143731 & $\begin{array}{l}\text { Guatimosim et al. } \\
\quad(2015)\end{array}$ \\
\hline Inocyclus angularis & VIC 39748 & $\begin{array}{l}\text { Brazil, epiphytic on } \\
\text { garden tree }\end{array}$ & KP143732 & $\begin{array}{l}\text { Guatimosim et al. } \\
\text { (2015) }\end{array}$ \\
\hline Jahnula aquatica & $\mathrm{R} 68-1 *$ & Unknown & EF175655 & $\begin{array}{l}\text { Campbell et al. } \\
\text { (2007) }\end{array}$ \\
\hline Jahnula bipileata & F49-1* & Unknown & EF175657 & $\begin{array}{l}\text { Campbell et al. } \\
\text { (2007) }\end{array}$ \\
\hline Jahnula seychellensis & $\mathrm{SS} 2113.1^{*}$ & Unknown & EF175665 & $\begin{array}{l}\text { Campbell et al. } \\
\text { (2007) }\end{array}$ \\
\hline $\begin{array}{l}\text { Keissleriella } \\
\text { cladophila }\end{array}$ & CBS 104.55 & $\begin{array}{l}\text { Pakistan, Smilax } \\
\text { parvifolia }\end{array}$ & JX681090 & Verkley et al. (2014) \\
\hline Latorua caligans & CBS 576.65 & Brazil, soil & KR873266 & Crous et al. (2015a) \\
\hline $\begin{array}{l}\text { Latorua } \\
\quad \text { grootfonteinensis }\end{array}$ & CBS 369.72 & Namibia, sandy soil & KR873267 & Crous et al. (2015a) \\
\hline Lembosia abaxialis & VIC 42825 & Brazil, Cerrado biome & KP143737 & $\begin{array}{l}\text { Guatimosim et al. } \\
\text { (2015) }\end{array}$ \\
\hline Lentithecium lineare & IFRD 2008 & Unknown & FJ795435 & Zhang et al. (2009b) \\
\hline $\begin{array}{l}\text { Leptosphaeria } \\
\text { conoidea }\end{array}$ & CBS 616.75 & $\begin{array}{l}\text { Netherlands, Lunaria } \\
\quad \text { апnиa }\end{array}$ & JF740279 & $\begin{array}{l}\text { de Gruyter et al. } \\
\text { (2013) }\end{array}$ \\
\hline $\begin{array}{l}\text { Leptosphaeria } \\
\text { doliolum }\end{array}$ & CBS 505.75 & $\begin{array}{l}\text { Netherlands, Urtica } \\
\quad \text { dioica }\end{array}$ & GQ387576 & $\begin{array}{l}\text { de Gruyter et al. } \\
\text { (2010) }\end{array}$ \\
\hline Leptoxyphium fumago & CBS 123.26 & $\begin{array}{l}\text { Indonesia, Hibiscus } \\
\quad \text { tiliaceus }\end{array}$ & GU214430 & Crous et al. (2009a) \\
\hline $\begin{array}{l}\text { Lophiostoma } \\
\text { arundinis }\end{array}$ & KT606 & $\begin{array}{l}\text { Japan, Phragmites } \\
\text { australis }\end{array}$ & AB618998 & $\begin{array}{l}\text { Hirayama and } \\
\text { Tanaka (2011) }\end{array}$ \\
\hline $\begin{array}{l}\text { Lophiostoma } \\
\text { macrostomum }\end{array}$ & KT508 & $\begin{array}{l}\text { Japan, Morus } \\
\text { bombycis }\end{array}$ & AB619010 & $\begin{array}{l}\text { Hirayama and } \\
\text { Tanaka (2011) }\end{array}$ \\
\hline $\begin{array}{l}\text { Macrodiplodiopsis } \\
\text { desmazieri }\end{array}$ & СРC 24972 & $\begin{array}{l}\text { Switzerland, Platanus } \\
\text { sp. }\end{array}$ & KR873273 & Crous et al. (2015a) \\
\hline $\begin{array}{l}\text { Macrodiplodiopsis } \\
\text { desmazieri }\end{array}$ & CBS 123811 & $\begin{array}{l}\text { Austria, Platanus } \times \\
\quad \text { acerifolia }\end{array}$ & KR873268 & Crous et al. (2015a) \\
\hline $\begin{array}{l}\text { Macrophomina } \\
\text { phaseolina }\end{array}$ & CBS 227.33 & Unknown, Zea mays & DQ377906 & Crous et al. (2006b) \\
\hline Massarina eburnea & H $3953 *$ & UK, Fagus sp. & AB521735 & $\begin{array}{l}\text { Hirayama et al. } \\
\quad(2010)\end{array}$ \\
\hline
\end{tabular}


Table 2 (continued)

\begin{tabular}{|c|c|c|c|c|}
\hline Species name & $\begin{array}{l}\text { Strain } \\
\text { accession } \\
\text { number }^{\mathrm{a}}\end{array}$ & Origin & $\begin{array}{l}\text { GenBank } \\
\text { accession } \\
\text { number }(\mathrm{LSU})^{\mathrm{b}}\end{array}$ & Reference \\
\hline Massarina eburnea & CBS 473.64 & $\begin{array}{l}\text { Switzerland, Fagus } \\
\quad \text { sylvatica }\end{array}$ & FJ201983 & Zhang et al. (2008) \\
\hline Medicopsis romeroi & CBS 252.60 & $\begin{array}{l}\text { Venezuela, } \\
\text { maduromycosis in } \\
\text { man }\end{array}$ & EU754207 & $\begin{array}{l}\text { Aveskamp et al. } \\
\text { (2010) }\end{array}$ \\
\hline $\begin{array}{l}\text { Melanomma } \\
\text { pulvis-pyrius }\end{array}$ & CBS 109.77 & Netherlands, Salix sp. & FJ201986 & Zhang et al. (2008) \\
\hline $\begin{array}{l}\text { Melanomma } \\
\text { pulvis-pyrius }\end{array}$ & CBS 124080 & France, Salix caprea & GU456323 & Zhang et al. (2009a) \\
\hline Microdochium majus & CBS 741.79 & $\begin{array}{l}\text { Germany, Triticum } \\
\text { aestivum }\end{array}$ & KP858937 & $\begin{array}{l}\text { Hernández-Restrepo } \\
\text { et al. (2016) }\end{array}$ \\
\hline Microdochium nivale & CBS 116205 & $\begin{array}{l}\text { England, Triticum } \\
\quad \text { aestivum }\end{array}$ & KP858944 & $\begin{array}{l}\text { Hernández-Restrepo } \\
\text { et al. (2016) }\end{array}$ \\
\hline $\begin{array}{l}\text { Morosphaeria } \\
\text { ramunculicola }\end{array}$ & BCC 18404 & $\begin{array}{l}\text { Malaysia, Mangrove } \\
\text { wood }\end{array}$ & GQ925853 & $\begin{array}{l}\text { Suetrong et al. } \\
\text { (2009) }\end{array}$ \\
\hline $\begin{array}{c}\text { Morosphaeria } \\
\text { velatispora }\end{array}$ & BCC 17059 & $\begin{array}{l}\text { USA, Mangrove } \\
\text { wood }\end{array}$ & GQ925852 & $\begin{array}{l}\text { Suetrong et al. } \\
\text { (2009) }\end{array}$ \\
\hline $\begin{array}{l}\text { Murilentithecium } \\
\text { clematidis }\end{array}$ & $\begin{array}{r}\text { MFLUCC } \\
14-0561\end{array}$ & Italy, Clematis vitalba & KM408758 & $\begin{array}{l}\text { Wanasinghe et al. } \\
\text { (2014) }\end{array}$ \\
\hline $\begin{array}{c}\text { Mycosphaerella } \\
\text { punctiformis }\end{array}$ & CBS 113265 & $\begin{array}{l}\text { Netherlands, Quercus } \\
\quad \text { robur }\end{array}$ & DQ470968 & $\begin{array}{l}\text { Spatafora et al. } \\
\text { (2006) }\end{array}$ \\
\hline $\begin{array}{c}\text { Neoascochyta } \\
\text { europaea }\end{array}$ & CBS 819.84 & $\begin{array}{l}\text { Germany, Hordeum } \\
\text { vulgare }\end{array}$ & KT389728 & Chen et al. (2015) \\
\hline $\begin{array}{l}\text { Neoascochyta } \\
\text { europaea }\end{array}$ & CBS 820.84 & $\begin{array}{l}\text { Germany, Hordeum } \\
\text { vulgare }\end{array}$ & KT389729 & Chen et al. (2015) \\
\hline Neoascochyta sp. & CBS 689.97 & Norway, hay & КT389744 & Chen et al. (2015) \\
\hline Neoascochyta sp. & CBS 516.81 & Italy, Oryza sativa & KT389743 & Chen et al. (2015) \\
\hline $\begin{array}{l}\text { Neophysalospora } \\
\text { eucalypti }\end{array}$ & CBS 138864 & $\begin{array}{l}\text { Mozambique, } \\
\text { Corymbia henryi }\end{array}$ & KP004490 & Crous et al. (2014c) \\
\hline $\begin{array}{l}\text { Neoscytalidium } \\
\text { dimidiatum }\end{array}$ & CBS 145.78 & UK, human foot & DQ377922 & Crous et al. (2006b) \\
\hline $\begin{array}{l}\text { Neoscytalidium } \\
\text { novaehollandiae }\end{array}$ & CMW 26170 & Unknown & KF766374 & Slippers et al. (2013) \\
\hline $\begin{array}{l}\text { Neottiosporina } \\
\text { paspali }\end{array}$ & CBS 331.37 & $\begin{array}{l}\text { USA, Paspalum } \\
\text { notatum }\end{array}$ & EU754172 & $\begin{array}{l}\text { de Gruyter et al. } \\
\text { (2009) }\end{array}$ \\
\hline $\begin{array}{l}\text { Ophiostoma } \\
\text { eucalyptigena }\end{array}$ & CBS 139899 & $\begin{array}{l}\text { Australia, Eucalyptus } \\
\quad \text { marginata }\end{array}$ & KR476756 & Crous et al. (2015b) \\
\hline Ophiostoma fusiforme & CMW9968 & $\begin{array}{l}\text { Azerbaijan, Populus } \\
\quad \text { nigra }\end{array}$ & DQ294354 & Zipfel et al. (2006) \\
\hline Ophiostoma ips & CMW7075 & USA, Ips integer & DQ294381 & Zipfel et al. (2006) \\
\hline Ophiostoma lunatum & CMW10564 & $\begin{array}{l}\text { Austria, Larix } \\
\text { deciduas }\end{array}$ & DQ294355 & Zipfel et al. (2006) \\
\hline $\begin{array}{l}\text { Ophiostoma } \\
\text { multiannulatum }\end{array}$ & CMW2567 & USA, Pinus & DQ294366 & Zipfel et al. (2006) \\
\hline $\begin{array}{l}\text { Ophiostoma } \\
\quad \text { nigrocarpum }\end{array}$ & CMW651 & $\begin{array}{l}\text { USA, Pseudotsuga } \\
\text { menziesii }\end{array}$ & DQ294356 & Zipfel et al. (2006) \\
\hline $\begin{array}{l}\text { Ophiostoma } \\
\text { novo-ulmi }\end{array}$ & CMW10573 & Austria, Picea abies & DQ294375 & Zipfel et al. (2006) \\
\hline Ophiostoma phasma & CMW20676 & Unknown & DQ316151 & Unpublished \\
\hline $\begin{array}{l}\text { Ophiostoma } \\
\text { pluriannulatum }\end{array}$ & CMW75 & Unknown & DQ294365 & Zipfel et al. (2006) \\
\hline $\begin{array}{l}\text { Ophiostoma } \\
\text { pulvinisporum }\end{array}$ & CMW9022 & $\begin{array}{l}\text { Mexico, Pinus } \\
\text { pseudostrobus }\end{array}$ & DQ294380 & Zipfel et al. (2006) \\
\hline $\begin{array}{l}\text { Ophiostoma } \\
\text { stenoceras }\end{array}$ & CMW3202 & Norway, pine pulp & DQ294350 & Zipfel et al. (2006) \\
\hline $\begin{array}{l}\text { Ophiostoma } \\
\text { thermarum }\end{array}$ & CMW38930 & $\begin{array}{l}\text { South Africa, } \\
\text { Euphorbia ingens }\end{array}$ & KR051127 & $\begin{array}{l}\text { van der Linde et al. } \\
\quad(2016)\end{array}$ \\
\hline
\end{tabular}


Table 2 (continued)

\begin{tabular}{|c|c|c|c|c|}
\hline Species name & $\begin{array}{l}\text { Strain } \\
\text { accession }^{\text {number }}\end{array}$ & Origin & $\begin{array}{l}\text { GenBank } \\
\text { accession } \\
\text { number }(\mathrm{LSU})^{\mathrm{b}}\end{array}$ & Reference \\
\hline Ophiostoma ulmi & CMW1462 & USA, Ulmus procer & DQ294374 & Zipfel et al. (2006) \\
\hline $\begin{array}{l}\text { Parabambusicola } \\
\text { bambusina }\end{array}$ & H 4321* & Japan, Sasa kurilensis & AB807536 & Tanaka et al. (2015) \\
\hline $\begin{array}{l}\text { Parabambusicola } \\
\text { bambusina }\end{array}$ & KH 139 & Japan, Sasa sp. & AB807537 & Tanaka et al. (2015) \\
\hline $\begin{array}{l}\text { Paraphaeosphaeria } \\
\text { michotii }\end{array}$ & CBS 652.86 & $\begin{array}{l}\text { Switzerland, Typha } \\
\text { latifolia }\end{array}$ & GQ387581 & $\begin{array}{l}\text { de Gruyter et al. } \\
\text { (2010) }\end{array}$ \\
\hline $\begin{array}{l}\text { Paraphaeosphaeria } \\
\quad \text { michotii }\end{array}$ & ETH 9483* & $\begin{array}{l}\text { Switzerland, Typha } \\
\quad \text { latifolia }\end{array}$ & JX496216 & Verkley et al. (2014) \\
\hline $\begin{array}{l}\text { Paraphaeosphaeria } \\
\text { minitans }\end{array}$ & CBS 122788 & UK, unknown host & EU754173 & $\begin{array}{l}\text { de Gruyter et al. } \\
\text { (2009) }\end{array}$ \\
\hline Parmularia styracis & VIC 42450 & $\begin{array}{l}\text { Brazil, conserved area } \\
\text { of Cerrado biome }\end{array}$ & KP143729 & $\begin{array}{l}\text { Guatimosim et al. } \\
\text { (2015) }\end{array}$ \\
\hline Parmularia styracis & VIC 42447 & $\begin{array}{c}\text { Brazil, conserved area } \\
\text { of Cerrado biome }\end{array}$ & KP143728 & $\begin{array}{l}\text { Guatimosim et al. } \\
\text { (2015) }\end{array}$ \\
\hline Parmularia styracis & VIC 42587 & $\begin{array}{l}\text { Brazil, abandoned } \\
\quad \text { area }\end{array}$ & KP143730 & $\begin{array}{l}\text { Guatimosim et al. } \\
\text { (2015) }\end{array}$ \\
\hline Patellaria cf. atrata & BCC 28876 & Unknown & GU371828 & Schoch et al. (2009a) \\
\hline Patellaria cf. atrata & BCC 28877 & Unknown & GU371829 & Schoch et al. (2009a) \\
\hline $\begin{array}{l}\text { Periconia } \\
\quad \text { macrospinosa }\end{array}$ & CBS 135663 & $\begin{array}{l}\text { Hungary, roots of host } \\
\text { of Festuca vaginata }\end{array}$ & KP184038 & Knapp et al. (2015) \\
\hline $\begin{array}{l}\text { Periconia } \\
\quad \text { pseudodigitata }\end{array}$ & KT 1395 & $\begin{array}{l}\text { Japan, Phragmites } \\
\text { australis }\end{array}$ & AB807564 & Tanaka et al. (2015) \\
\hline $\begin{array}{l}\text { Periconia } \\
\quad \text { pseudodigitata }\end{array}$ & KT 1195A & $\begin{array}{l}\text { Japan, submerged } \\
\text { herbaceous plant }\end{array}$ & AB807563 & Tanaka et al. (2015) \\
\hline $\begin{array}{l}\text { Phaeocryptopus } \\
\text { gaeumannii }\end{array}$ & CBS 267.37 & $\begin{array}{l}\text { Germany, } \\
\text { Phaeocryptopus } \\
\text { gaeumannii }\end{array}$ & EF114698 & Winton et al. (2007) \\
\hline $\begin{array}{l}\text { Phaeotrichum } \\
\text { benjaminii }\end{array}$ & CBS 541.72 & $\begin{array}{l}\text { Unknown, dung of } \\
\text { rodent }\end{array}$ & AY779311 & $\begin{array}{l}\text { Lumbsch et al. } \\
\text { (2005) }\end{array}$ \\
\hline $\begin{array}{l}\text { Plectosphaera } \\
\text { eucalypti }\end{array}$ & CBS 120063 & $\begin{array}{l}\text { Australia, Eucalyptus } \\
\text { orbifolia }\end{array}$ & DQ923538 & $\begin{array}{l}\text { Summerell et al. } \\
\text { (2006) }\end{array}$ \\
\hline Pleospora herbarum & CBS 191.86 & $\begin{array}{l}\text { India, Medicago } \\
\quad \text { sativa }\end{array}$ & GU238160 & $\begin{array}{l}\text { Aveskamp et al. } \\
\text { (2010) }\end{array}$ \\
\hline $\begin{array}{l}\text { Polyschema } \\
\text { congolensis }\end{array}$ & CBS 542.73 & Zaire, soil & EF204502 & Unpublished \\
\hline $\begin{array}{l}\text { Polyschema } \\
\text { larviformis }\end{array}$ & CBS 463.88 & Turkey, soil & EF204503 & Unpublished \\
\hline Polyschema terricola & CBS 301.65 & Brazil, soil & EF204504 & Unpublished \\
\hline $\begin{array}{l}\text { Prillieuxina } \\
\quad \text { baccharidincola }\end{array}$ & VIC 42817 & Brazil, unknown host & KP143735 & $\begin{array}{l}\text { Guatimosim et al. } \\
\quad(2015)\end{array}$ \\
\hline $\begin{array}{l}\text { Pseudobeltrania } \\
\text { ocoteae }\end{array}$ & СРC 26219 & $\begin{array}{l}\text { La Reunion, Ocotea } \\
\quad \text { sp. }\end{array}$ & KT950870 & Unpublished \\
\hline $\begin{array}{l}\text { Pseudocercospora } \\
\text { fijiensis }\end{array}$ & $\begin{array}{l}\text { AFTOL-ID } \\
2021\end{array}$ & Unknown & DQ678098 & Unpublished \\
\hline $\begin{array}{l}\text { Pseudocercospora } \\
\quad \text { vitis }\end{array}$ & CPC 11595 & $\begin{array}{l}\text { South Korea, Vitis } \\
\quad \text { vinifera }\end{array}$ & JX901912 & $\begin{array}{l}\text { Quaedvlieg et al. } \\
\text { (2012) }\end{array}$ \\
\hline $\begin{array}{l}\text { Pseudodictyosporium } \\
\text { elegans }\end{array}$ & CBS 688.93 & $\begin{array}{l}\text { Taiwan, decaying } \\
\text { stem }\end{array}$ & DQ018106 & Unpublished \\
\hline $\begin{array}{l}\text { Pseudodictyosporium } \\
\text { wauense }\end{array}$ & $\begin{array}{l}\text { NBRC } \\
30078\end{array}$ & Japan, decayed leaf & DQ018105 & Unpublished \\
\hline $\begin{array}{l}\text { Psiloglonium } \\
\text { simulans }\end{array}$ & CBS 206.34 & USA, Tilia & FJ161178 & Boehm et al. (2009) \\
\hline $\begin{array}{l}\text { Pyrenochaeta } \\
\text { quercina }\end{array}$ & CBS 115095 & Italy, Quercus robur & GQ387619 & $\begin{array}{l}\text { de Gruyter et al. } \\
\quad(2010)\end{array}$ \\
\hline
\end{tabular}


Table 2 (continued)

\begin{tabular}{|c|c|c|c|c|}
\hline Species name & $\begin{array}{l}\text { Strain } \\
\text { accession }^{\mathrm{n}} \\
\text { number }^{\mathrm{a}}\end{array}$ & Origin & $\begin{array}{l}\text { GenBank } \\
\text { accession } \\
\text { number }(\mathrm{LSU})^{\mathrm{b}}\end{array}$ & Reference \\
\hline $\begin{array}{c}\text { Pyrenochaeta } \\
\text { quercina }\end{array}$ & CBS 297.74 & Montenegro, sea water & GQ387620 & $\begin{array}{l}\text { de Gruyter et al. } \\
\text { (2010) }\end{array}$ \\
\hline $\begin{array}{l}\text { Rhytidhysteron } \\
\text { rufulum }\end{array}$ & CBS 306.38 & $\begin{array}{l}\text { Unknown, Pistacia } \\
\text { chinensis }\end{array}$ & FJ469672 & Schoch et al. (2009b) \\
\hline Rosellinia necatrix & $\begin{array}{c}\text { HKUCC } \\
9037\end{array}$ & Unknown & AY083824 & Unpublished \\
\hline Roussoella acaciae & CBS 138873 & $\begin{array}{l}\text { Tanzania, Acacia } \\
\text { tortilis }\end{array}$ & KP004497 & Crous et al. (2014c) \\
\hline $\begin{array}{l}\text { Roussoella } \\
\quad \text { percutanea }\end{array}$ & CBS 128203 & India, Homo sapiens & KF366448 & Ahmed et al. (2014) \\
\hline $\begin{array}{l}\text { Roussoella } \\
\text { percutanea }\end{array}$ & CBS 868.95 & Aruba, Homo sapiens & KF366449 & Ahmed et al. (2014) \\
\hline $\begin{array}{l}\text { Roussoella } \\
\text { scabrispora }\end{array}$ & $\begin{array}{r}\text { MFLUCC } \\
11-0624\end{array}$ & Thailand, bamboo & KJ474844 & Liu et al. (2014) \\
\hline $\begin{array}{l}\text { Saccharomyces } \\
\text { cerevisiae }\end{array}$ & $\begin{array}{l}\text { DAOM } \\
216365\end{array}$ & Unknown & JN938921 & Schoch et al. (2012) \\
\hline Schizothyrium pomi & CBS 228.57 & Italy, unknown host & EF134947 & Batzer et al. (2008) \\
\hline Schizothyrium pomi & CBS 486.50 & $\begin{array}{l}\text { Netherlands, } \\
\text { Polygonum } \\
\text { sachalinense }\end{array}$ & EF134948 & Batzer et al. (2008) \\
\hline Seimatosporium sorbi & $\begin{array}{r}\text { MFLUCC } \\
14-0469\end{array}$ & Italy, unknown host & KT281911 & Unpublished \\
\hline Seimatosporium vitis & $\begin{array}{r}\text { MFLUCC } \\
14-0051\end{array}$ & Italy, Vitis vinifera & KR920362 & $\begin{array}{l}\text { Senanayake et al. } \\
\text { (2015) }\end{array}$ \\
\hline Seiridium cardinale & CBS 172.56 & Unknown & AF382376 & Jeewon et al. (2002) \\
\hline Seiridium papillatum & CBS 340.97 & $\begin{array}{l}\text { Tasmania, Eucalyptus } \\
\text { delegatensis }\end{array}$ & DQ414531 & Unpublished \\
\hline Seiridium phylicae & СРC 19965 & UK, Phylica arborea & KC005809 & Crous et al. (2012) \\
\hline Seiridium phylicae & СРC 19962 & UK, Phylica arborea & NG042759 & Crous et al. (2012) \\
\hline Sporothrix inflata & CMW12527 & $\begin{array}{l}\text { Germany, host soil in } \\
\text { wheat field }\end{array}$ & DQ294351 & Zipfel et al. (2006) \\
\hline Sporothrix pallida & CBS 131.56 & $\begin{array}{l}\text { South Africa, } \\
\text { sporophore }\end{array}$ & EF139121 & $\begin{array}{l}\text { de Meyer et al. } \\
\text { (2008) }\end{array}$ \\
\hline Sporothrix schenckii & CMW7614 & $\begin{array}{l}\text { South Africa, human } \\
\text { sporotrichosis }\end{array}$ & DQ294352 & Zipfel et al. (2006) \\
\hline Sporothrix stylites & CMW14543 & $\begin{array}{l}\text { South Africa, wood } \\
\text { pole }\end{array}$ & EF139115 & $\begin{array}{l}\text { de Meyer et al. } \\
(2008)\end{array}$ \\
\hline $\begin{array}{l}\text { Stagonospora } \\
\text { paludosa }\end{array}$ & CBS 135088 & $\begin{array}{l}\text { Netherlands, Carex } \\
\text { acutiformis }\end{array}$ & KF251760 & $\begin{array}{l}\text { Quaedvlieg et al. } \\
\text { (2013) }\end{array}$ \\
\hline $\begin{array}{l}\text { Stagonospora } \\
\text { pseudocaricis }\end{array}$ & S610* & $\begin{array}{r}\text { France, Carex } \\
\text { acutiformis }\end{array}$ & KF251763 & $\begin{array}{l}\text { Quaedvlieg et al. } \\
\text { (2013) }\end{array}$ \\
\hline Sulcatispora acerina & KT 2982 & Japan, Acer palmatum & LC014610 & Tanaka et al. (2015) \\
\hline $\begin{array}{l}\text { Sulcatispora } \\
\text { berchemiae }\end{array}$ & KT 1607 & $\begin{array}{l}\text { Japan, Berchemia } \\
\text { racemosa }\end{array}$ & AB807534 & Tanaka et al. (2015) \\
\hline $\begin{array}{l}\text { Teratosphaeria } \mathrm{cf} . \\
\quad \text { bellula }\end{array}$ & CPC 18280 & $\begin{array}{l}\text { South Africa, } \\
\quad \text { Phaenocoma } \\
\text { prolifera }\end{array}$ & JF499864 & $\begin{array}{l}\text { Crous and } \\
\text { Groenewald } \\
\text { (2011) }\end{array}$ \\
\hline $\begin{array}{l}\text { Teratosphaeria } \\
\quad \text { fibrillosa }\end{array}$ & CBS 121707 & $\begin{array}{l}\text { South Africa, Protea } \\
\text { sp. }\end{array}$ & KF902075 & $\begin{array}{l}\text { Quaedvlieg et al. } \\
\text { (2014) }\end{array}$ \\
\hline $\begin{array}{l}\text { Teratosphaeria } \\
\quad \text { stellenboschiana }\end{array}$ & CBS 116428 & $\begin{array}{l}\text { South Africa, } \\
\text { Eucalyptus sp. }\end{array}$ & EU019295 & Crous et al. (2007a) \\
\hline $\begin{array}{l}\text { Teratosphaeria } \\
\text { suberosa }\end{array}$ & CPC 11032 & $\begin{array}{l}\text { Colombia, Eucalyptus } \\
\text { sp. }\end{array}$ & GU214512 & Crous et al. (2009a) \\
\hline Torula ficus & CBS 595.96 & Cuba, Ficus religiosa & KF443385 & Ahmed et al. (2014) \\
\hline Torula herbarum & CBS 140066 & & KR873288 & Crous et al. (2015a) \\
\hline
\end{tabular}


Table 2 (continued)

\begin{tabular}{|c|c|c|c|c|}
\hline Species name & $\begin{array}{l}\text { Strain } \\
\text { accession }^{\text {number }}\end{array}$ & Origin & $\begin{array}{l}\text { GenBank } \\
\text { accession } \\
\text { number }(\mathrm{LSU})^{\mathrm{b}}\end{array}$ & Reference \\
\hline & & $\begin{array}{l}\text { Netherlands, } \\
\text { Phragmites } \\
\text { australis }\end{array}$ & & \\
\hline Torula hollandica & CBS 220.69 & $\begin{array}{l}\text { Netherlands, } \\
\text { Delphinium sp. }\end{array}$ & KF443384 & Ahmed et al. (2014) \\
\hline Torula masonii & CBS 245.57 & UK, Brassica sp. & KR873289 & Crous et al. (2015a) \\
\hline $\begin{array}{l}\text { Trematosphaeria } \\
\text { pertusa }\end{array}$ & CBS 122371 & France, Platanus sp. & FJ201992 & Zhang et al. (2008) \\
\hline $\begin{array}{l}\text { Trematosphaeria } \\
\text { pertusa }\end{array}$ & CBS 122368 & $\begin{array}{l}\text { France, Fraxinus } \\
\quad \text { excelsior }\end{array}$ & FJ201990 & Zhang et al. (2008) \\
\hline $\begin{array}{l}\text { Trichodelitschia } \\
\text { bisporula }\end{array}$ & CBS 262.69 & $\begin{array}{l}\text { Netherlands, dung of } \\
\text { rabbit }\end{array}$ & GU348996 & Schoch et al. (2009a) \\
\hline Tubeufia paludosa & CBS 120503 & USA, rotten wood & GU301877 & Schoch et al. (2009a) \\
\hline Venturia inaequalis & CBS 176.42 & $\begin{array}{l}\text { France, Pyracantha } \\
\text { coccinea }\end{array}$ & GU348998 & Schoch et al. (2009a) \\
\hline Venturia populina & CBS 256.38 & $\begin{array}{r}\text { Italy, Populus } \\
\text { canadensis }\end{array}$ & GU323212 & Schoch et al. (2009a) \\
\hline Vialaea mangifia & $\begin{array}{r}\text { MFLUCC } \\
12-0808\end{array}$ & $\begin{array}{l}\text { Thailand, Mangifera } \\
\quad \text { indica }\end{array}$ & KF724975 & $\begin{array}{l}\text { Senanayake et al. } \\
\text { (2014) }\end{array}$ \\
\hline Vialaea minutella & BRIP 56959 & $\begin{array}{l}\text { Australia, Mangifera } \\
\quad \text { indica }\end{array}$ & KC181924 & $\begin{array}{l}\text { McTaggart et al. } \\
\text { (2013) }\end{array}$ \\
\hline $\begin{array}{l}\text { Wojnowiciella } \\
\text { eucalypti }\end{array}$ & CBS 139904 & $\begin{array}{l}\text { Colombia, Eucalyptus } \\
\text { grandis }\end{array}$ & KR476774 & Crous et al. (2015b) \\
\hline Wojnowiciella viburni & $\begin{array}{l}\text { MFLUCC } \\
120733 b\end{array}$ & China, Viburnum utile & KC594287 & Unpublished \\
\hline Xylaria frustulosa & ANM 1300 & USA, unknown host & JN673055 & Raja et al. (2011) \\
\hline
\end{tabular}

${ }^{a}$ AFTOL: Assembling the Fungal Tree of Life project; ANM: A.N. Miller personal collection; AR: Amy Y. Rossman personal collection; BCC: Belgian Coordinated Collections of Microorganisms; BRIP: Plant Pathology Herbarium, Department of Agriculture, Fisheries and Forestry, Queensland, Australia; CABI: International Mycological Institute, CABI-Bioscience, Bakeham Lane, Egham, UK; CBS: Westerdijk Fungal Biodiversity Centre, Utrecht, The Netherlands; CMW: Mike Wingfield personal collection; CPC: Collection Pedro Crous; DAOM: Plant Research Institute, Department of Agriculture (Mycology), Ottawa, Canada; GKM: G.K. Mugambi personal collection; HHUF: Herbarium of Hirosaki University, Japan; HKUCC: University of Hong Kong Culture Collection, Department of Ecology and Biodiversity, Hong Kong, China; ICMP: International Collection of Microorganisms from Plants, Plant Diseases Division, DSIR, Auckland, New Zealand; IFRDCC: Culture Collection, International Fungal Research \& Development Centre, Chinese Academy of Forestry, Kunming, China; KT: K. Tanaka personal collection; MFLUCC/MFLU: Mae Fah Luang University Culture Collection, Chiang Rai, Thailand; NBRC: NITE Biological Resource Centre, Japan; VIC: Herbarium of the Universidade Federal de Viçosa. *Strain designation from GenBank

${ }^{\mathrm{b}}$ LSU: partial 28S nrDNA

best-fit nucleotide substitution model for the ML analysis. Spumatoria longicollis was placed on a single branch, phylogenetically separated from the species included (De Beer et al. 2013, 2016; van der Linde et al. 2016).

\section{The genera}

Aleurocystis Lloyd ex G. Cunn., Trans. \& Proc. Roy. Soc. N.Z. 84: 234 (1956).

Synonym: Matula Massee, J. Roy. Microscop. Soc. 4: 176 (1888).

Classification: Incertae sedis, Agaricales, Agaricomycetes.
Current generic circumscription: Basidiomata annual, as small pustules, cupulate-discoid to resupinate with raised margin, pale ochre to light pink, gelatinous when fresh, horny when dry. Hyphal system monomitic, generative hyphae thin- to thick-walled, with clamps. Lamprocystidia (metuloid cystidia) present, hymenial to subhymenial, thick-walled. Gloeocystidia present in one species. Dendrohyphidia present in some species, usually only slightly branched. Basidia clavate, with four sterigmata. Basidiospores large, subglobose to ellipsoid, walls thin, smooth, non-amyloid.

Type species: Aleurocystis hakgallae (Berk. \& Broome) G. Cunn. 1956. 
Fig. 1 Maximum composite likelihood tree based on the analysis from the partial LSU sequences from species included in different orders from Dothideomycetes. Bootstrap support values above $70 \%$ are shown at the nodes. Clades are delineated based on the phylogeny of Guatimosim et al. (2015). The tree was rooted with Saccharomyces cerevisiae

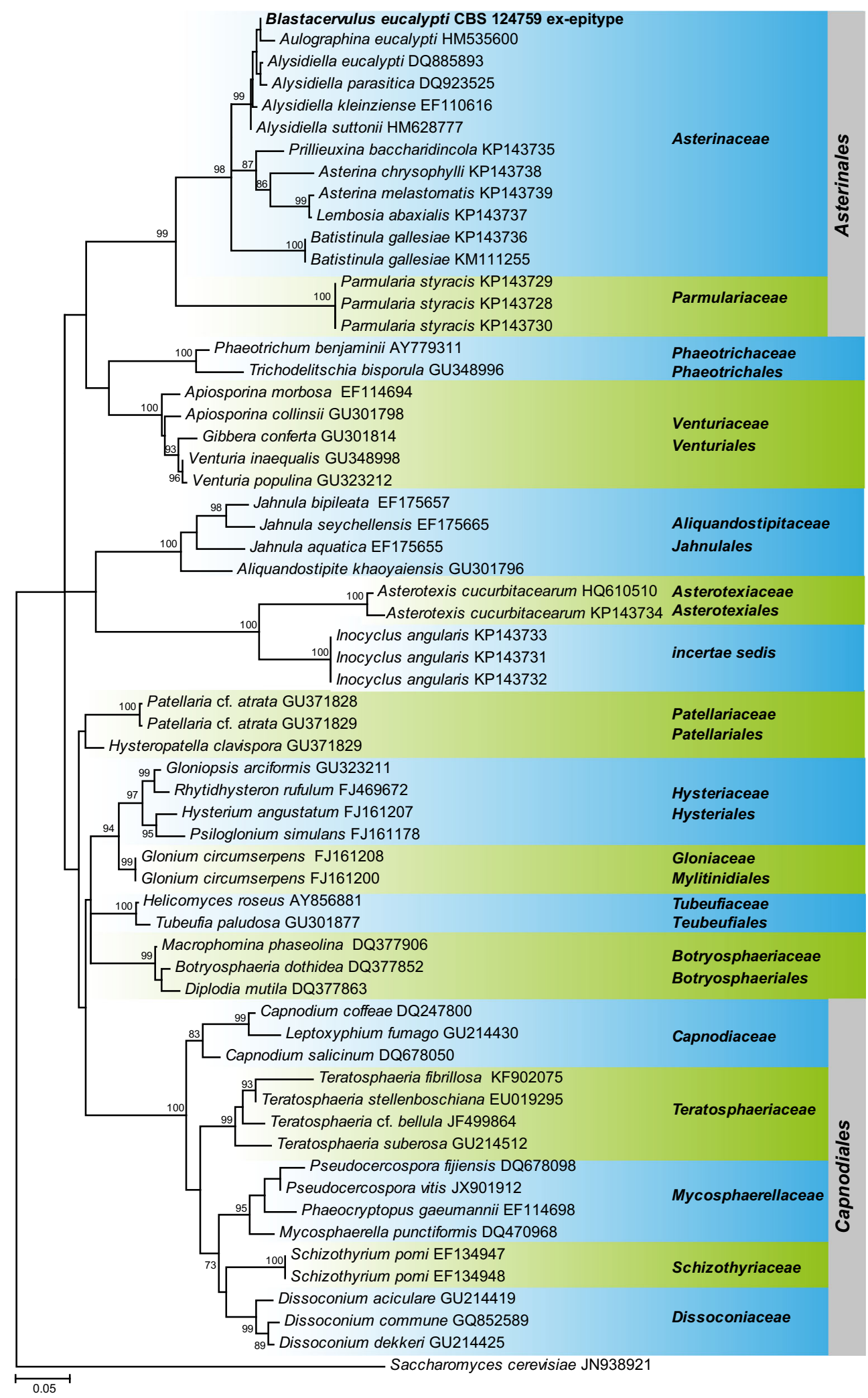


Fig. 2 Maximum composite likelihood tree based on the analysis from the partial LSU sequences from species included in different families from Xylariales. Bootstrap support values above $70 \%$ are shown at the nodes. Species from which their LSU sequences were generated here are shown in bold. The tree was rooted with Diaporthe padi and D. perjuncta (Diaporthales)

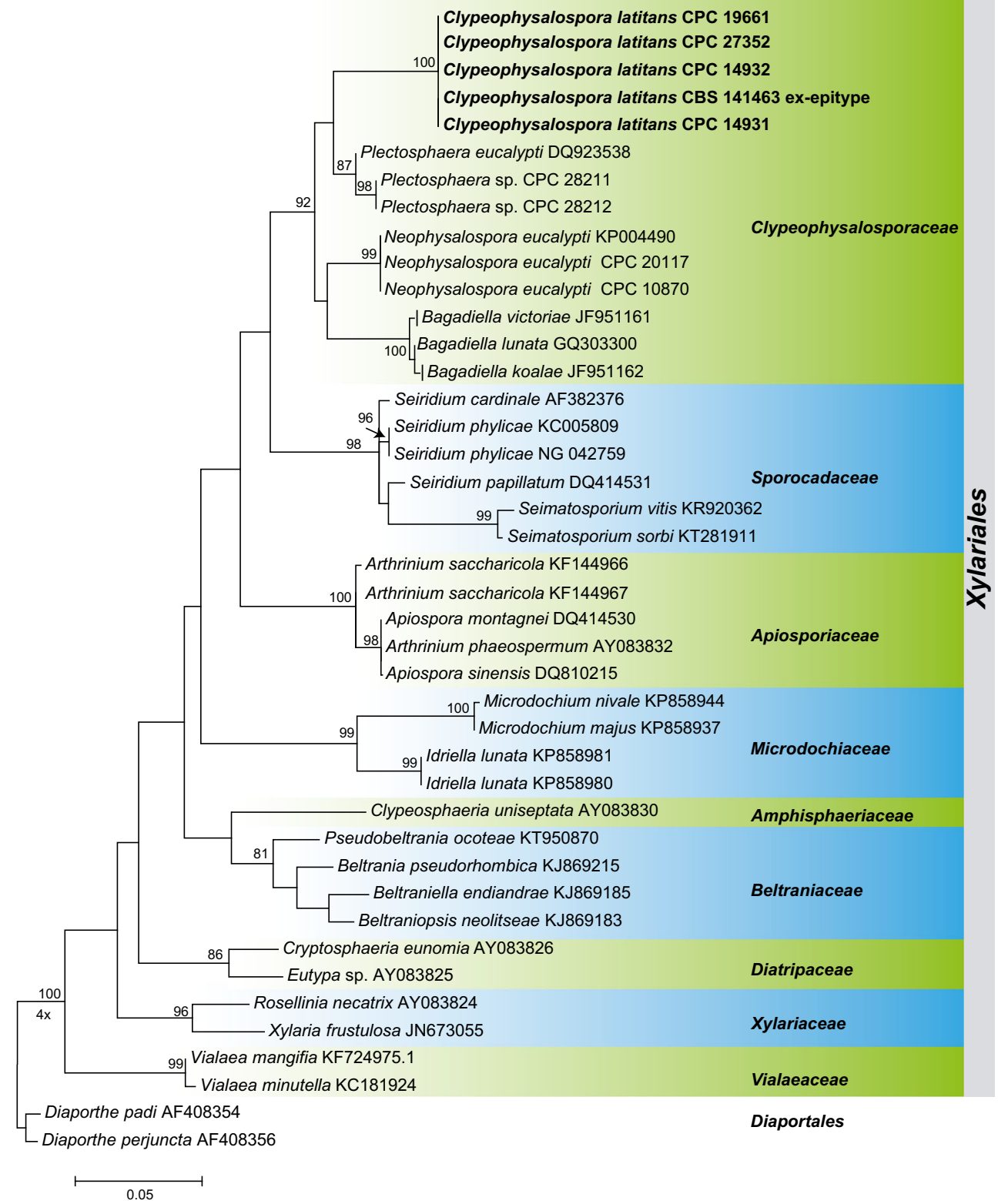

Aleurocystis hakgallae (Berk. \& Broome) G. Cunn. [as 'habgallae'], Trans. \& Proc. Roy. Soc. N.Z. 84: 235 (1956). Fig. 5a, b

MycoBank: MB 292367

Basionym. Corticium hakgallae Berk. \& Broome [as 'habgallae'], J. Linn. Soc., Bot. 14: 72 (1873) [1875].

Synonyms. Peniophora hakgallae (Berk. \& Broome) Cooke, Grevillea 8: 20 (1879).

Matula poroniiforme (Berk. \& Broome) Massee [as 'poroniaeformis'], J. Roy. Microscop. Soc. 4: 176 (1888).

Cytidia cornea Lloyd, Mycol. Writ. 5: 656 (1917).

Aleurodiscus capensis Lloyd, Mycol. Writ. 6 (Letter 62): 930 (1920).

Cytidia hakgallae (Berk. \& Broome) G.W. Martin, Lloydia 5: 160 (1942).
Aleurodiscus hakgallae (Berk. \& Broome) Donk, Persoonia 1: 68 (1959).

Description: Basidiomata annual, cupulate-discoid to resupinate with raised margin, as small separate pustules, round to orbicular, about $5 \mathrm{~mm}$ in diam., more thickened in the middle, texture (in dried material) dense cartilaginous. Abhymenial surface more or less smooth, few hyaline hairs may be present. Hymenial surface whitish cream to pale ochre, smooth.

Fig. 3 Maximum composite likelihood tree based on the analysis from the partial LSU sequences from species included in different families from Pleosporales. Bootstrap support values above $70 \%$ are shown at the nodes. Clades are delineated based on the phylogeny of Tanaka et al. (2015). Species from which their LSU sequences were generated here are shown in bold. The tree was rooted with Neoscytalidium novaehollandiae and $N$. dimidiatum (Botryosphaeriales) 
100 Neoascochyta sp. KT389744

${ }_{95}$ Neoascochyta sp. KT389743

Neoascochyta europaea KT389728

${ }_{100}$ Neoascochyta europaea KT389729

Leptosphaeria doliolum GQ387576

100 Leptosphaeria conoidea JF740279.1

Cochliobolus sativus DQ678045

${ }_{100}$ Pleospora herbarum CBS 191.86 GU238160

${ }_{100}$ Wojnowiciella eucalypti KR476774

Wojnowiciella viburni KC594287

5 Pyrenochaeta quercina GQ387619

Pyrenochaeta quercina GQ387620

Cucurbitaria berberidis KC506793

${ }_{99}$ Cucurbitaria berberidis GQ387605

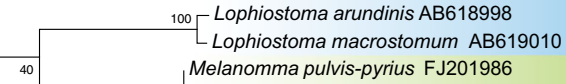

Melanomma pulvis-pyrius FJ201986

${ }_{100}$ Melanomma pulvis-pyrius GU456323

Didymellaceae

Leptosphaeriaceae

Pleosporaceae

Phaeosphaeriaceae

Cucurbitaceae

Lophiostomataceae

Melanommataceae

Ascocylindrica marina KT252906

Ascocylindrica marina KT252905

100 Medicopsis romeroi KF015621

Medicopsis romeroi EU754207

Neohendersonia sp. CPC 24865

Ascocylindricaceae

incertae sedis

Neohendersonia kickxii CBS 114276

98 Neohendersonia kickxii CBS 122938

Neohendersonia kickxii CBS 122941

Morosphaeria ramunculicola GQ925853

$100 \_$Morosphaeria velatispora GQ925852

Corynespora torulosa KF777207

${ }_{100}-$ Corynespora cassiicola GU301808

Corynespora smithii GU323201

- Periconia macrospinosa KP184038

100 Periconia pseudodigitata AB807564

${ }_{99}$ Periconia pseudodigitata AB807563

100 Macrodiplodiopsis desmazieri KR873273

Macrodiplodiopsis desmazieri KR873268

Trematosphaeria pertusa FJ201992

100 Trematosphaeria pertusa FJ201990

- Paraphaeosphaeria minitans EU754173

Paraphaeosphaeria michotii GQ387581

${ }_{100}$ Paraphaeosphaeria michotii JX496216

Massarina eburnea FJ201983

Massarina eburnea AB521735

100 Stagonospora paludosa KF251760

Stagonospora pseudocaricis KF251763

83 L Neottiosporina paspali EU754172

- Helminthosporium velutinum AB807529

- Helminthosporium massarinum AB807523

Helminthosporium dalbergiae AB807521

0.05 Helminthosporium magnisporum AB807522

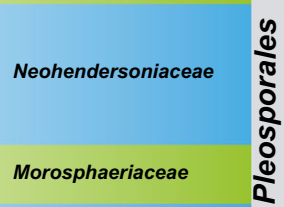

Corynesporascaceae

Periconiaceae

Macrodiplodiopsidaceae

Trematosphaeriaceae

Didymosphaeriaceae

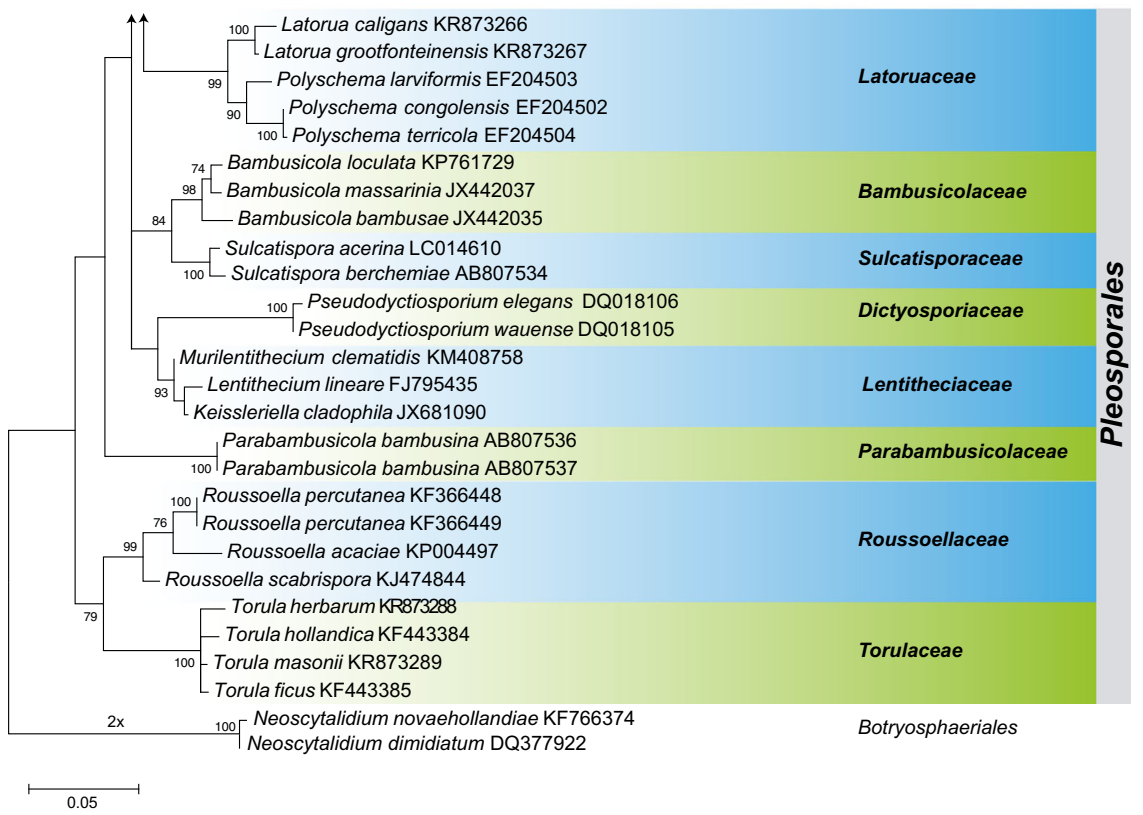


Fig. 4 Maximum composite likelihood tree based on the analysis from the partial LSU sequences from species included in the Ophiostoma and Sporothrix clades from the Ophiostomatales according to De Beer et al. (2016) and van der Linde et al. (2016). Bootstrap support values above $70 \%$ are shown at the nodes. Species from which their LSU sequences were generated here are shown in bold. The tree was rooted with Ceratocystiopsis species (Ophiostomatales)

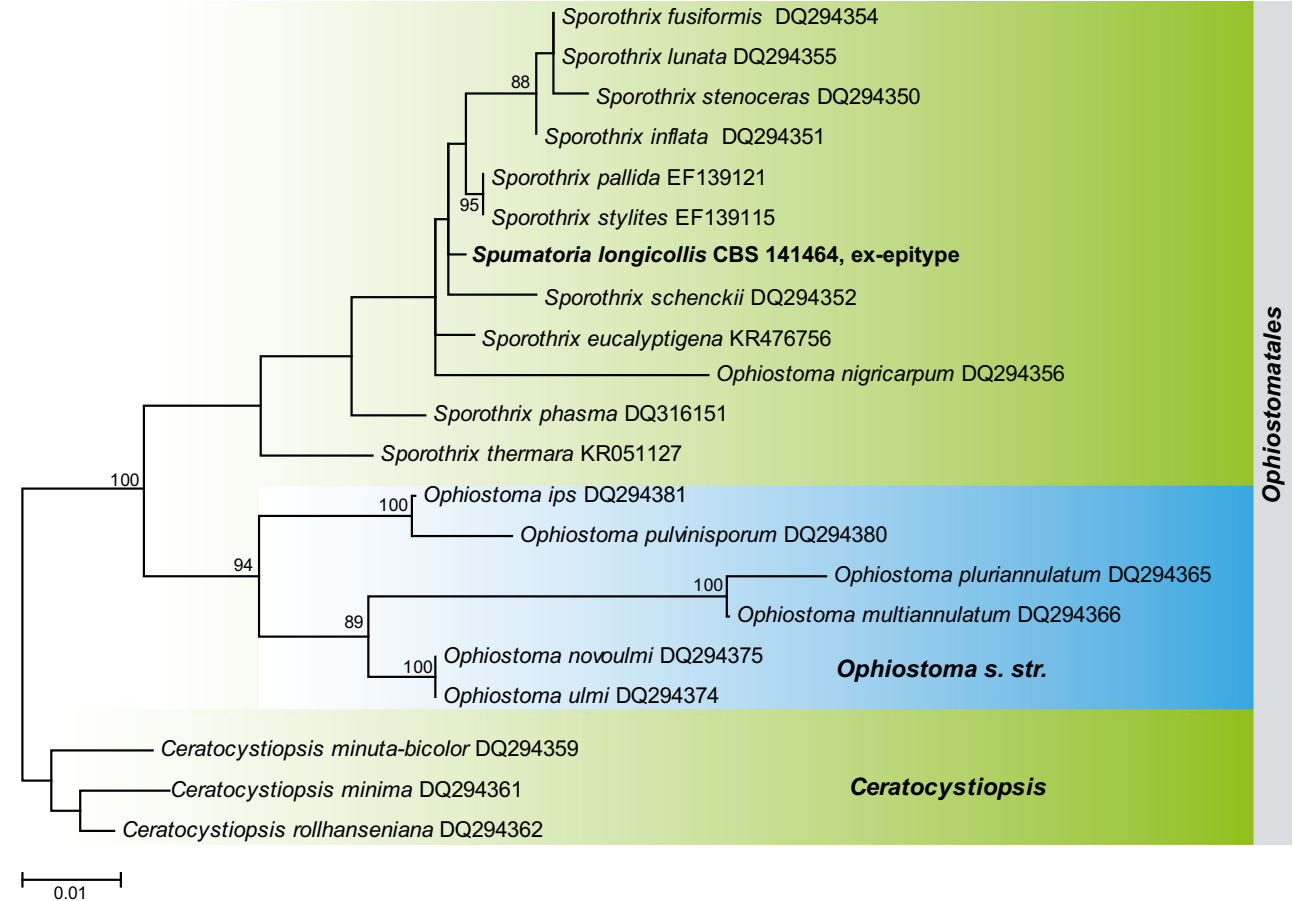

gelatinised in $\mathrm{KOH}$, intricate and difficult to discern, 4$7 \mu \mathrm{m}$ wide, hymenial elements with granular, oily substances
Hyphal system monomitic, all hyphae with clamps, thinwalled in the subhymenium, thick-walled in subiculum,
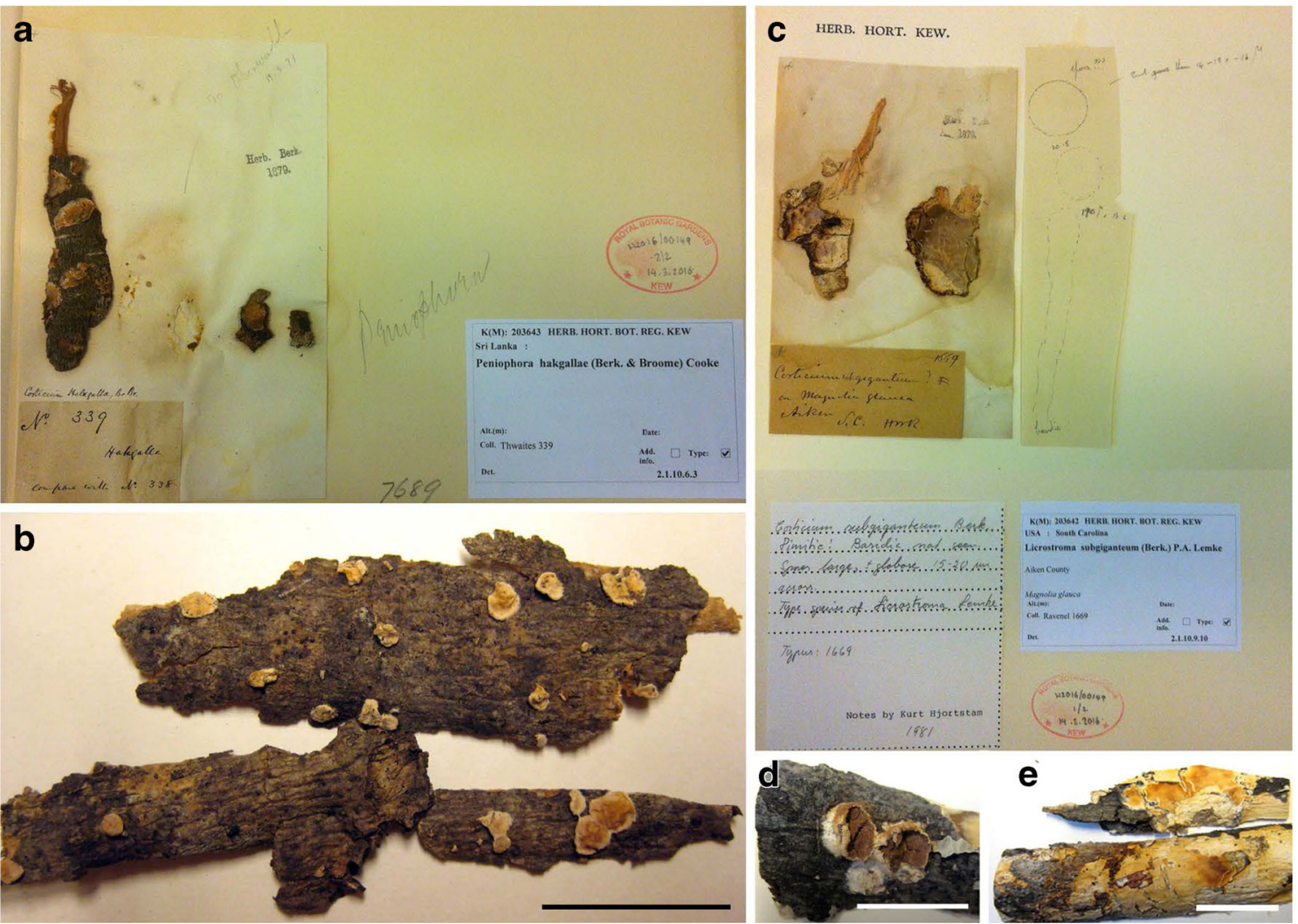

Fig. 5 Species of Corticium, Aleurocystis and Licrostroma. a Corticium hakgallae (holotype, K). b Aleurocystis hakgallae (Gilbertson RLG23290, CFMR). c Corticium subgiganteum (holotype, K). d
Conidiomata of Licrostroma subgiganteum (Pinette RJP-7289, CFMR). e Basidiomata of Licrostroma subgiganteum (Pinette RJP-7290, CFMR). Scale bars: $2 \mathrm{~cm}$ 
as seen in $\mathrm{KOH}$ (large acicular crystals present on hymenial and tramal hyphae in RLG-23290). Subiculum thin, subicular hyphae branched, 3-9 $\mu \mathrm{m}$ wide. Lamprocystidia (metuloid cystidia) present in hymenium and subhymenium, thickwalled, conical, acute, coarsely encrusted in upper half, more or less ventricose and stalked in the subhymenium, slightly projecting above the hymenial layer, 50-140 ×9-14 $\mu \mathrm{m}$, hyaline. Dendrohyphidia scattered among basidia, littlebranched in the upper part, widened in the lower, unbranched part, about $40-50 \times 4.5-7 \mu \mathrm{m}$. Basidia clavate to cylindrical, $50-80 \times 12-18 \mu \mathrm{m}$, bearing four sterigmata. Basidiospores large, subglobose to widely ellipsoid, with a small, prominent apiculus, thin-walled, hyaline, smooth, with granular, oily substances as seen in $\mathrm{KOH}$, negative in Melzer's reagent, 16-23 $\times 13-16 \mu \mathrm{m}$. Conidia globose, thick-walled, walls 2.5-3 $\mu \mathrm{m}$ thick, smooth, negative in Melzer's reagent, 17 $20 \mu \mathrm{m}$ in diameter.

Specimens examined: Sri Lanka, Hakgala, on dead bark of an angiosperm tree, sine dat., Thwaites 339 [K(M) 203643 - holotype]. USA, Hawaii, Bird park, HUNP, Kau District County, on Sapindus saponaria, 15 Jan. 2000, Gilbertson RLG-23290 (CFMR - reference material designated here); ex-reference material sequences, GenBank nos. KX358899 (ITS), KX358900 (LSU).

Notes: The genus Aleurocystis, typified with A. hakgallae, comprises three corticioid species with cupuloid to discoid basidiomes, lamprocystidia, monomitic hyphal system with clamped hyphae, and large, non-amyloid basidiospores. Morphologically, the genus was assumed by Ryvarden (1998) to be related to the genera Cytidia (in Corticiales) and Aleurodiscus (in Russulales). We scrutinised the bibliographic literature on the generic type to locate its original material. In his study on types of corticioid fungi described by M. J. Berkeley, Hjortstam (1989) also listed C. 'habgallae' as the generic type for Aleurocystis. Upon an inquiry to $\mathrm{K}$ herbarium, we received a material filed as Peniophora hakgallae (Fig. 5a). The material contains a handwritten name and number matching the protologue by Berkeley and Broome (1875). Therefore, we are of the opinion that K(M) 203643 represents the original material of Corticium hakgallae. No conidial stage was detected on this $\mathrm{K}(\mathrm{M})$ 203643 specimen. The specimen from CFMR (Fig. 5b) morphologically conforms the type and we could obtain ITS and LSU sequences from it.

A MegaBLAST search of the GenBank nucleotide database at NCBI (as of 25 May 2016) showed that the best three hits using the new LSU sequence were Gloeostereum incarnatum, Baeospora myosura and Xeromphalina campanella, with $94-95 \%$ identity over $100 \%$ query coverage. Using the new ITS sequence, the best hits were Tephrocybe cf. carbonaria and Lyophyllum spp., with 82$83 \%$ identity over $91 \%$ query coverage. Therefore,
Aleurocystis sensu typi is shown to belong to the order Agaricales.

Authors: M. Ghobad-Nejhad and E. Langer

Blastacervulus H.J. Swart, Trans. Br. Mycol. Soc. 90: 289 (1988).

Classification: Asterinaceae, Asterinales, Dothideomycetes

Current generic circumscription: Foliicolous, plant pathogenic. Conidiomata acervular, brown, subcuticular with a single layer of brown epidermal cells; conidioma with brown hyphal threads, verruculose, septate, 3-4 $\mu \mathrm{m}$ diam., giving rise to conidia in a sympodial fashion, holoblastic. Conidia in a dry powdery mass, globose to ellipsoidal, medium brown, thickwalled, verruculose, guttulate, frequently in chains of two, at times with a thin mucoid sheath, base truncate, unthickened.

Type species: Blastacervulus eucalypti H.J. Swart 1988.

Blastacervulus eucalypti H.J. Swart, Trans. Br. Mycol. Soc. 90: 289 (1988). Fig. 6

MycoBank: MB 133297

Description: Leaf spots not extending through leaf lamina; circular to subcircular or irregular, 2-6 mm diam., becoming confluent, brown, raised with a yellow halo. Conidiomata acervular, up to $350 \mu \mathrm{m}$ diam., brown, subcuticular with a single layer of brown epidermal cells, frequently arranged in a radiating pattern, or in circles, from centre of leaf spot. Conidioma with brown hyphal threads, verruculose, septate, 3-4 $\mu \mathrm{m}$ diam., giving rise to conidia in a sympodial fashion, holoblastic. Conidia in a dry powdery mass, globose to ellipsoidal, medium brown, thick-walled, verruculose, guttulate, frequently in chains of two, at times with a thin mucoid sheath, base truncate, unthickened, 2-3 $\mu \mathrm{m}$ diam., apex obtuse, (4)6-7(8) $\times(4) 5-6 \mu \mathrm{m}$.

Culture characteristics: Colonies on MEA and SNA attaining $10 \mathrm{~mm}$ diam. after 1 month at $25^{\circ} \mathrm{C}$, black, membranous with scarce aerial mycelium.

Specimens examined: Australia, Victoria, Calder Highway near Woodend, on living leaves of Eucalyptus obliqua, 13 Oct. 1979, H.J. Swart (holotype DAR 58998); Mullion Creek, on Eucalyptus robertsonii subsp. hemisphaerica, 26 Jan. 2007, B.A. Summerell (epitype designated here, CBS H-20278, MycoBank MBT373086; culture ex-epitype CBS $124759=$ CPC 13956).

Notes: Swart (1988) regarded B. eucalypti as reminiscent of the genus Staninwardia, but distinct in having thallic, 1-septate conidia with truncate, flat hila. Phylogenetically, the two genera are members of Dothideomycetes, but according to the phylogeny of Cheewangkoon et al. (2009), Staninwardia (represented by $S$. suttoni) is closely related to Capnodiales, and recently it was accommodated in the Extremaceae (Quaedvlieg et al. 2014). Blastacervulus, on the other hand, belongs to Asterinales. Another similar genus is the monotypic Fairmaniella (Sutton 1980), but in the case of F. eucalypti, 

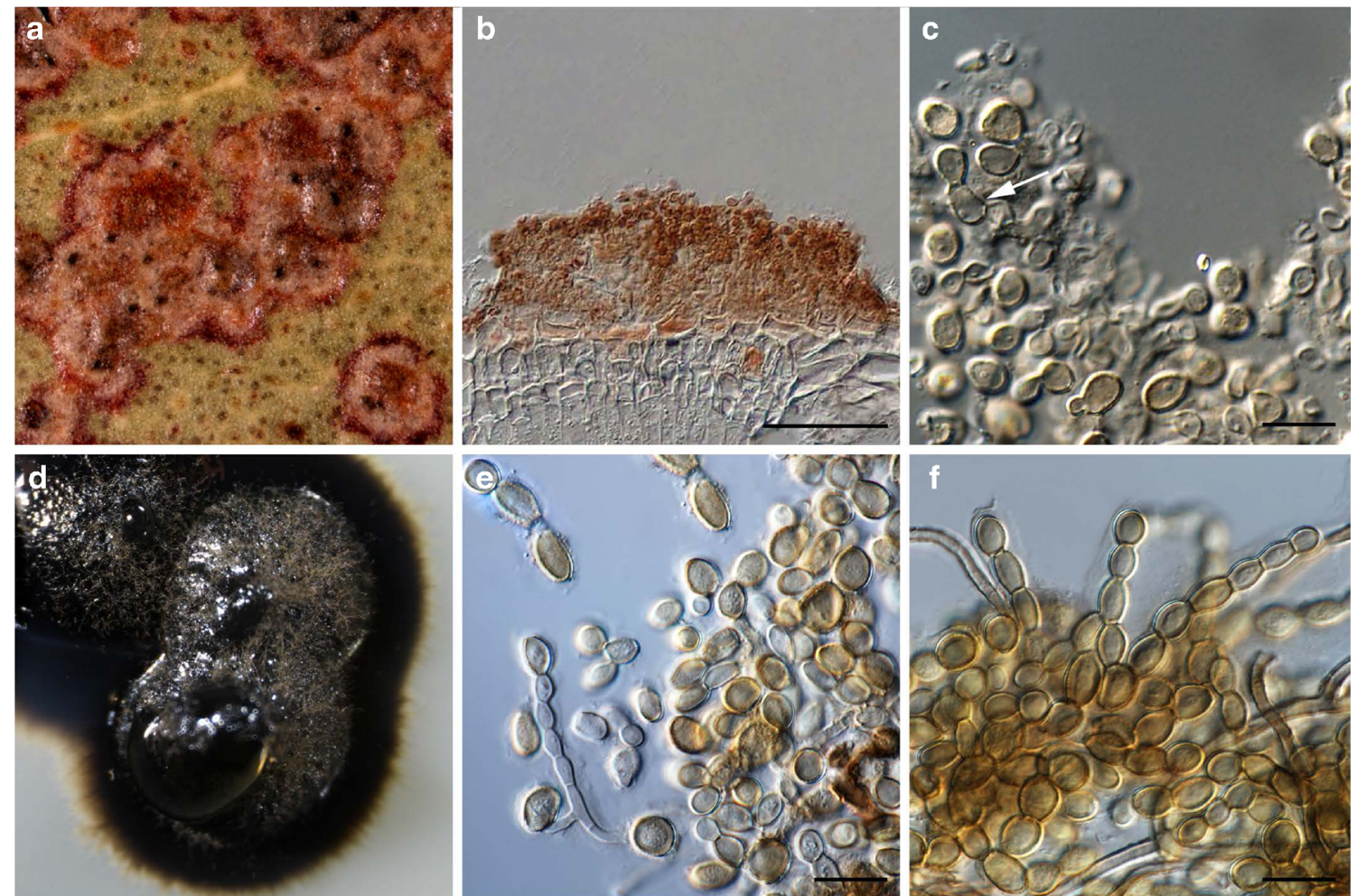

Fig. 6 Blastacervulus eucalypti (CBS 124759). a Leaf symptoms. b Vertical sections through conidioma c Conidiogenous cells (arrow) and conidia from leaves. $\mathbf{d}$ Colony sporulating on MEA. e, $\mathbf{f}$ Conidia in chains. Scale bars: $\mathbf{b}=100 \mu \mathrm{m}$, all others $=10 \mu \mathrm{m}$

conidia are smaller (4-7.5 × 3-4.5 $\mu \mathrm{m})$ and ellipsoid-fusoid in shape. The LSU analysis showed that B. eucalypti belongs to Asterinaceae (Asterinales), which includes species forming foliicolous or lichenicolous, superficial, dark brown to black colonies (Hyde et al. 2013; Guatimosim et al. 2015). Blastacervulus eucalypti is closely related with Aulographina eucalypti and Alysidiella species (Fig. 1), all of them associated with target spot and chocolate spot disease on Eucalyptus, respectively (Cheewangkoon et al. 2012).

\section{Authors: A. Giraldo and P.W. Crous}

Clypeophysalosporaceae Giraldo \& Crous, fam. nov.

MycoBank: MB 818514

Description: Endophytic, saprobic or plant pathogenic. Ascomata perithecial, brown or black, immersed, single, rarely in pairs, globose, sometimes with clypeus or pseudoclypeus, wall of several layers of brown and flattened cells. Asci mixed with paraphyses, cylindrical or obclavate, hyaline, unitunicate, 8-spored, with apical mechanism staining in Melzer's reagent. Ascospores uniseriate or biseriate, unicellular, hyaline, fusoidal-ellipsoidal, commonly surrounded by a mucoid sheath. Asexual morph coelomycetes or hyphomycetes. Conidiomata pycnidial, globose, solitary to aggregated, brown. Conidiophores differentiated or reduced to conidiogenous cells (pycnidial form), forming fascicules or rosettes on leaves, or solitary on the hyphae (hyphomycetal form), cylindrical to subcylindrical, brown to pale grey-brown. Conidiogenous cells phialidic, ampulliform, lageniform or subcylindrical, terminal and intercalary, pale to medium brown, apex with flared collarette. Conidia solitary or in slimy heads, subcylindrical, curved, hyaline, obtuse apex and truncate to subtruncate base.

Type genus: Clypeophysalospora H.J. Swart. 1981.

Type species: Clypeophysalospora latitans (Sacc.) H.J. Swart.

Genera included: Bagadiella, Clypeophysalospora, Neophysalospora and Plectosphaera.

Clypeophysalospora H.J. Swart, Trans. Br. Mycol. Soc. 76: 93 (1981).

Classification: Clypeophysalosporaceae, Xylariales, Sordariomycetes.

Current generic circumscription: Ascomata perithecial, scattered, immersed, single or rarely in pairs, covered by a dark clypeus, with a wall consisting of darkened, flattened, thin-walled cells and with a narrow periphysate ostiole. Asci paraphysate, cylindrical or slightly swollen, unitunicate, with an amyloid apical ring and a pulvillus. Ascospores mostly uniseriate or irregularly arranged, hyaline, ellipsoid, with mucous outer wall layer. Asexual morph unknown.

Type species: Clypeophysalospora latitans (Sacc.) H.J. Swart 1981.

Clypeophysalospora latitans (Sacc.) H.J. Swart, Trans. Br. Mycol. Soc. 76: 95 (1981). Fig. 7 

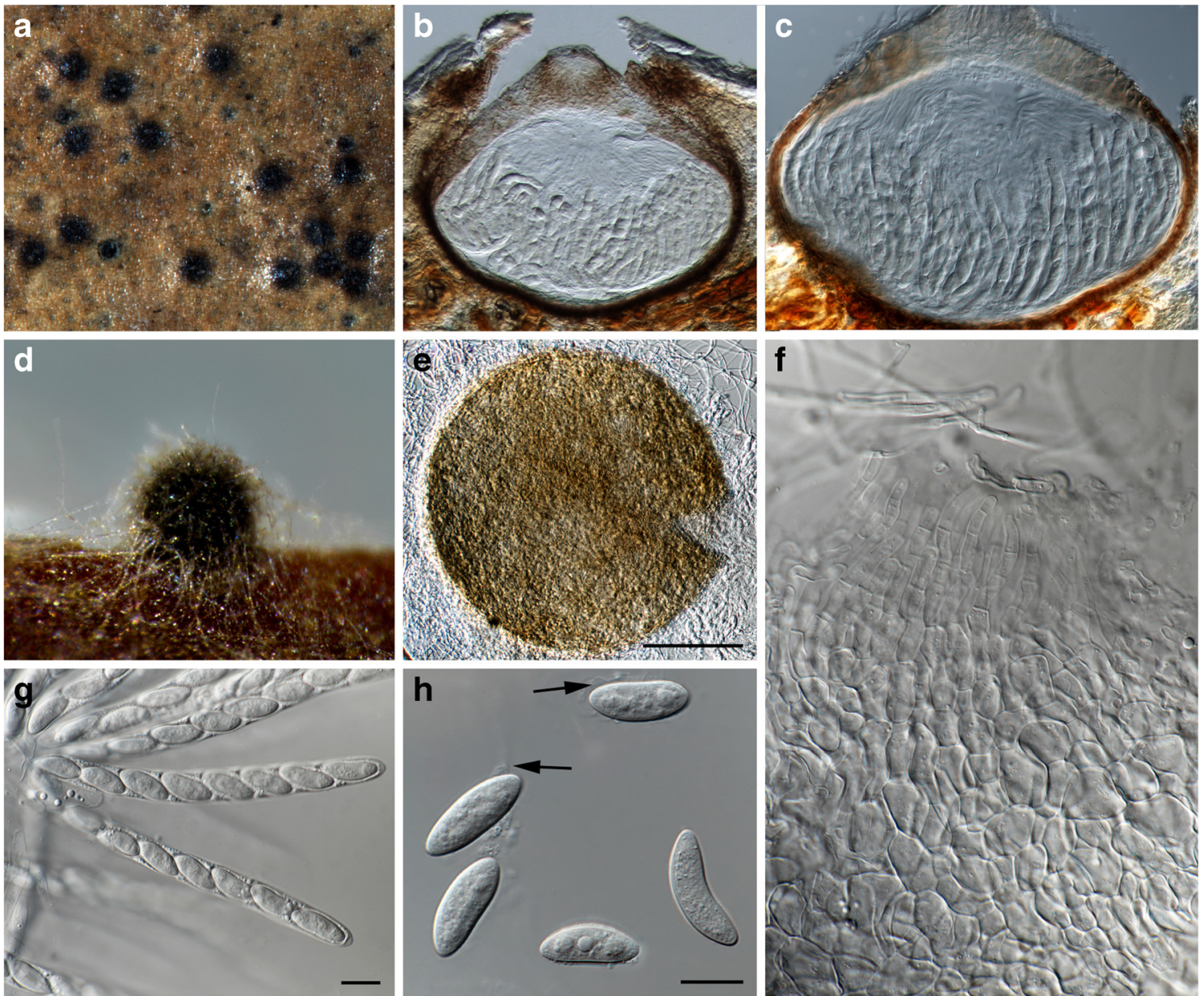

Fig. 7 Clypeophysalospora latitans (CPC 14930). a Leaf symptoms. b, c Vertical sections through ascoma. d Ascoma on PNA. e Ascoma. f Details of ostiolar region and peridium. $\mathbf{g}$ Asci. $\mathbf{h}$ Ascospores (arrows denote mucoid sheaths). Scale bars: $\mathbf{e}=50 \mu \mathrm{m}$, all others $=10 \mu \mathrm{m}$

\section{MycoBank: MB 112195}

Basionym. Physalospora latitans Sacc. Flora. Myc. Lusitan. 67 (1893).

Synonym. Amerostege latitans (Sacc.) Theiss. Annales. Mycologici. 14: 411 (1917).

Description: Ascomata visible as erumpent, hemispherical, brown on the host surface; in vertical section 320-450 $\mu \mathrm{m}$ diam., immersed, globose, clypeate, with a central periphysate ostiolar canal, surface of textura epidermoidea or globosa. Peridium 13-16 $\mu \mathrm{m}$ wide, comprising several layers of brown compressed cells. Clypeus composed of dark brown compressed host cells and fungal hyphae. Paraphyses up to $6.4 \mu \mathrm{m}$ in diam., hypha-like, flexuose, septate, numerous, hyaline and embedded in a gelatinous matrix. Asci 8-spored, cylindrical, unitunicate, thin-walled, with a $\mathrm{J}+$ and an amyloid apical ring, in vivo $115-141 \times 11-$ $16 \mu \mathrm{m}$, in vitro $(107) 108-117(118) \times 9-10 \mu \mathrm{m}$. Ascospores uniseriate, unicellular, ellipsoidal, slightly curved, smooth-walled, in vivo $13-22 \times 6-9 \mu \mathrm{m}$, in vitro (11)13-19(20) × 5-7 $\mu \mathrm{m}$, hyaline, surrounded by a thin mucilaginous sheath. Asexual morph not observed.
Culture characteristics: Colonies on OA and MEA attaining $10 \mathrm{~mm}$ diam. after 3 weeks at $25^{\circ} \mathrm{C}$, flat, floccose to granulose, dirty white to pale rose.

Specimens examined: France, Corsica, Porto-Vecchio, on living leaves of Eucalyptus sp., 2 May 2005, P. W. Crous (CPC 27352). Portugal, Algarve, Faro, on living leaves of Eucalyptus sp., 24 Jan. 2008, P. W. Crous (epitype designated here, CBS H-20289, MycoBank MBT373087; culture exepitype CBS $141463=$ CPC 14930, CPC 14931, CPC 14932); Beira Litoral, Coímbra (PAD 2747 lectotype). South Africa, Stellenbosch Mountain, on living leaves of Eucalyptus sp., 8 Aug. 2011, P. W. Crous (CPC 19661).

Notes: After the morphological examination of fresh material of Clypeophysalospora latitans, Kang et al. (1999) considered that the presence of immersed and clypeate ascomata, among other morphological characteristics, were similar to those observed in the genus Clypeosphaeria, and, therefore, $C$. latitans was accommodated in Clypeosphaeriaceae together with the other 16 allied genera (Kang et al. 1999). However, no molecular data were provided at that time. Although the type species of that family is Clypeosphaeria mamillana, Senanayake et al. 
(2015) used the LSU and ITS sequences of $C$. uniseptata (the only species from the genus having living culture at that moment) to demonstrate the affinity of this family with the order Amphisphaeriales, previously considered as a family in the Xylariales. However, presently, the Amphisphaeriales is no longer accepted as a separate order, and it is treated as one of the families in Xylariales (Crous et al. 2015a; Maharachchikumbura et al. 2016). Recently, C. mamillana has been epitypified and the polyphyly of the genus has been demonstrated (Jaklitsch et al. 2016). Clypeosphaeria mamillana belongs to Xylariaceae and C. uniseptata was combined in Lepteutypa (Amphisphaeriaceae). In consequence, the concept of the family Clypeosphaeriaceae (based on C. uniseptata; Senanayake et al. 2015) is no longer valid (Jaklitsch et al. 2016).

We have included the sequence of $C$. uniseptata in our LSU analysis (Fig. 2) and, according to our results, this species is not related at the family level with Clypeophysalospora latitans, and, therefore, we have proposed a new family to accommodate the latter taxon. The members of the new family, i.e. Bagadiella, Clypeophysalospora, Neophysalospora and Plectosphaerella, share morphological characteristics with each other, in terms of both sexual and asexual morph, host specificity (mainly Eucalyptus spp.) and distribution (Australia, South Africa). However, in the case of $N$. eucalypti, it has also been isolated from Corymbia henryi (Myrtaceae) in Mozambique and C. latitans was originally described on Eucalyptus leaves from Europe (Swart 1981; Cheewangkoon et al. 2009; Crous et al. 2011, 2014c).

\section{Authors: A. Giraldo and P.W. Crous}

Licrostroma P.A. Lemke, Canad. J. Bot. 42: 762 (1964). Synonym: Michenera Berk. \& M.A. Curtis, J. Linn. Soc., Bot. 10: 333 (1868) [1869].

Classification: Peniophoraceae, Russulales, Agaricomycetes.

Current generic circumscription: Basidiomata resupinate to effused-reflexed, smooth, cream to ochre, confluent, more or less membranaceous. Hyphal system dimitic, generative hyphae simple-septate, binding hyphae as 'bovista-type', antlerlike, branched hyphae especially present in basal layers, negative in Melzer's reagent. Dendrohyphidia present, simple and little-branched. Cystidia smooth, long cylindrical to subclavate, thin- to thick-walled, flexuous, with rounded or tapering apices, not projecting above the hymenium. Basidia large, clavate to cylindrical, with four strigmata. Basidiospores large, globose to subglobose, thick-walled, smooth, negative in Melzer's reagent.

Conidial state (see Fig. 5d): Conidiomata cupulate, brown, rounded, ca. $1 \mathrm{~cm}$ wide, with yellowish cream outer surface, attached centrally to the substratum, composed of chlamydospores and simple-septate hyphae. Chlamydospores fusoid, walls brown, 3-3.5 $\mu \mathrm{m}$ thick, smooth.
Type species: Licrostroma subgiganteum (Berk.) P.A. Lemke 1964.

Licrostroma subgiganteum (Berk.) P.A. Lemke, Canad. J. Bot. 42: 763 (1964). Fig. 5d, e MycoBank: MB 333369

Basionym. Corticium subgiganteum Berk., Grevillea 2: 3 (1873).

Synonyms. Peniophora subgigantea (Berk.) Massee, J. Linn. Soc., Bot. 25: 142 (1889).

Terana subgigantea (Berk.) Kuntze, Revis. Gen. P1. (Leipzig) 2: 873 (1891).

Aleurodiscus subgiganteus (Berk.) Höhn., Sber. Akad. Wiss. Wien, Math.-Natur. Kl. Sitzungsb. 121: 342 (1912).

Michenera artocreas Berk. \& M.A. Curtis, J. Linn. Soc., Bot. 10: 333 (1868).

Aleurodiscus orientalis Lloyd, Mycol. Writ. 6 (Letter 62): 927 (1920).

Aleurodiscus reflexus Yasuda, Bot. Mag., Tokyo 35 (no. 420): 269 (1921).

Description and illustration: Lemke (1964), Ryvarden (2010).

Specimens examined. USA, South Carolina, Aiken, on Magnolia glauca, sine dat., Ravenel 1669 (K(M)203642 holotype); Maine, Aroostook, on dead snag of Acer rubrum, 31 Oct. 2006, R. J. Pinette RJP-7289 (CFMR - reference material designated here); ex-reference material sequences, GenBank nos. KX358901, KX358903 (ITS); KX358902, KX358904 (LSU).

Notes: Licrostroma is a monotypic genus of corticioid basidiomycetes. It has thick, effused-reflexed basidiomes with compact texture, a dimitic hyphal system, simple-septate generative hyphae and branched binding-like hyphae called 'bovista-type hyphae' by Lemke (1964), who proposed the genus to be related to Aleurodiscus. Indeed, the 'bovista-type' hyphae mentioned by Lemke (1964) somehow resemble dichohyphae in Scytinostroma and asterosetae (asterohyphae) in Asterostroma. Licrostroma and Scytinostroma, as well as Asterostroma, are dimitic and have simple-septate generative hyphae (except for a few Scytinostroma species, which have clamps). However, unlike the two latter genera, Licrostroma does not react with Melzer's reagent.

We examined two specimens at CFMR, one containing only brown conidiomata (Fig. 5d) and the other specimen with resupinate basidiomata (Fig. 5e). Both samples have been collected on the same date and substratum, and from the same locality. We obtained the ITS and LSU sequences from both specimens and believe that they represent the same species, probably a single collection divided into sexual and asexual specimens. Morphologically, the CFMR collection conforms to the original material of Corticium subgiganteum (Fig. 5c) that we received from $\mathrm{K}$. We could also observe some chlamydospores within the hyphae of the $\mathrm{K}$ type specimen. 
A MegaBLAST search of the GenBank nucleotide database at NCBI (as of 25 May 2016) showed that the top hits using the new LSU sequences of $L$. subgiganteum were Scytinostroma spp., Asterostroma spp. and Gloiothele spp. [all in Peniophoraceae sensu Miller et al. (2006)], with 9294\% identity over $97-100 \%$ coverage. Using the new ITS sequences, the top hits were Scytinostroma and Gloiothele, as well as hits of Helicobasidium and Tuberculina maxima (asexual morph Helicobasidium). Although we are not able to interpret the latter hits, the morphological similarities between Licrostroma and Scytinostroma/Asterostroma described above suggest their close relationships. Upon this, Licrostroma sensu typi is proposed to belong to Peniophoraceae, Russulales.

\section{Authors: M. Ghobad-Nejhad and E. Langer}

Neohendersoniaceae Giraldo \& Crous, fam. nov.

MycoBank MB 818515.

Description: Conidiomata single or gregarious, immersed, globose to collabent, papillate, dark brown to black, unilocular or multilocular; wall thick, of textura porrecta, intricata or angularis. Ostiole single, papillate. Conidiophores reduced to conidiogenous cells. Conidiogenous cells discrete, determinate or indeterminate, cylindrical, lageniform, doliiform or ampulliform, hyaline, smooth, with percurrent proliferations. Conidia obovoid, cylindrical, clavate or fusiform, distoseptate or euseptate, basal or apical cells paler than the median cells, thick-walled, base truncate, apex obtuse.

Type genus: Neohendersonia Petr., 1921.

Type species: Neohendersonia kickxii (Westend.) Sutton \& Pollack.

Neohendersonia Petr., Annls Mycol. 19 (3-4): 190 (1921). Classification: Neohendersoniaceae, Pleosporales, Dothideomycetes.

Current generic circumscription: Mycelium immersed, branched, septate, pale brown. Conidiomata pycnidial, eustromatic, separate or aggregated, immersed, globose or collabent, papillate, dark brown to black, uni- or multilocular, thick-walled, the outer one dark brown with textura porrecta or intricata, and the inner one hyaline with textura angularis. Ostiole single, circular, papillate. Conidiophores reduced to conidiogenous cells. Conidiogenous cells holoblastic, single or annellidic, discrete, determinate or indeterminate, cylindrical, lageniform, doliiform or ampulliform, hyaline, smooth, with 0-3 percurrent proliferations. Conidia obovoid, cylindrical, clavate or fusiform, transversely distoseptate or euseptate, versicoloured, basal and sometimes apical cells paler than the median cells, thick-walled, smooth, truncated at base, obtuse at the apex, eguttulate.
Type species: Neohendersonia kickxii (Westend.) Sutton and Pollack 1974.

Neohendersonia kickxii (Westend.) Sutton \& Pollack, Mycopath. Mycol. Appl. 52: 334 (1974). Fig. 8

MycoBank: MB 318608

Basionym. Stilbospora kickxii Westend., Bull. Acad. R. Sci. Belg., Cl. Sci. 18: 409 (1851).

Synonyms. Hendersonia loricata Sacc. \& Roum., Michelia 2 (8): 629 (1882).

Coryneum kickxii (Westend.) Traverso, Bol. Soc. Bot. Ital. 215 (1904).

Neohendersonia pyriformis (G.H. Otth) Petr., Annls Mycol. 19 (3-4): 191 (1921).

Stilbospora pyriformis (G.H. Otth) Grove, British Stemand Leaf-Fungi (Coelomycetes) (Cambridge) 2: 326 (1937).

Description: Conidiomata pycnidial, separate or aggregated, immersed, subperidermal, not protruding, black, smooth, ampulliform, uni- or multilocular, up to $1300 \mu \mathrm{m}$ diam., outer layer dark brown, $30 \mu \mathrm{m}$ wide, inner layer pale brown becoming hyaline towards the conidiogenous cells, 40-60 $\mu \mathrm{m}$ wide. Ostiole single, circular, up to $250 \mu \mathrm{m}$ diam., slightly papillate, thin-walled and pale brown. Conidiogenous cells holoblastic, annellidic, with up to seven annellations, discrete, hyaline, smooth, cylindrical to obpyriform, in vivo $4-9 \times 2-6 \mu \mathrm{m}$, in vitro $6-9 \times 6-8 \mu \mathrm{m}$. Conidia solitary, obovoid to clavate, pyriform 2-3 distoseptate, slightly constricted at the prominent septa, apical cell larger than the other ones, thick- and smoothwalled, apex obtuse, base truncated, brown with paler basal cell, in vivo $21-45.5 \times 12.5-20 \mu \mathrm{m},(2) 3(6)$-celled and seldom with one longitudinal septum per conidium, in vitro (20)22-26(28) $\times$ $11-14 \mu \mathrm{m}$. Microconidia were observed in culture growing directly from the hyphae, cylindrical with rounded apex and truncate base, hyaline, thick- and smooth-walled, $2-4 \times 2-3 \mu \mathrm{m}$.

Culture characteristics: Colonies on MEA and OA black, flat, cottony, aerial mycelium dirty white, diffusible amber pigment, reverse honey to isabelline.

Specimens examined: Austria, Carinthia, Sankt Margareten im Rosental, on Fagus sylvatica, unknown date, W. Jaklitsch (CBS 122938); Grieskirchen, Natternbach, on Fagus sylvatica, unknown date, H. Voglmayr (CBS 122941). Belgium, Courtrai, Parc Saint-George, on branch of Fagus sylvatica ("substrate originally determined as Betula pubescens and later corrected with Fagus sylvatica"), Mar. G.D. Westendorp (holotype IMI 168433 ex BR). Germany, mixed forest, on twigs of Fagus sylvatica, 19 Apr. 2014, R.K. Schumacher (CPC 24865). Italy, Pian di Novello, on bark of twigs from Fagus sylvatica, 8 May 1996, R. Danti (epitype designated here, MycoBank MBT373088; culture ex-epitype CBS 112403). Sweden, Uppland, on Fagus sp. 12 Mar 1989, K. \& L. Holm (CBS $114276=$ UPSC 2890).

Notes: Neohendersonia was established by Petrak (1921) based on Neohendersonia pyriforme, described from Fagus 

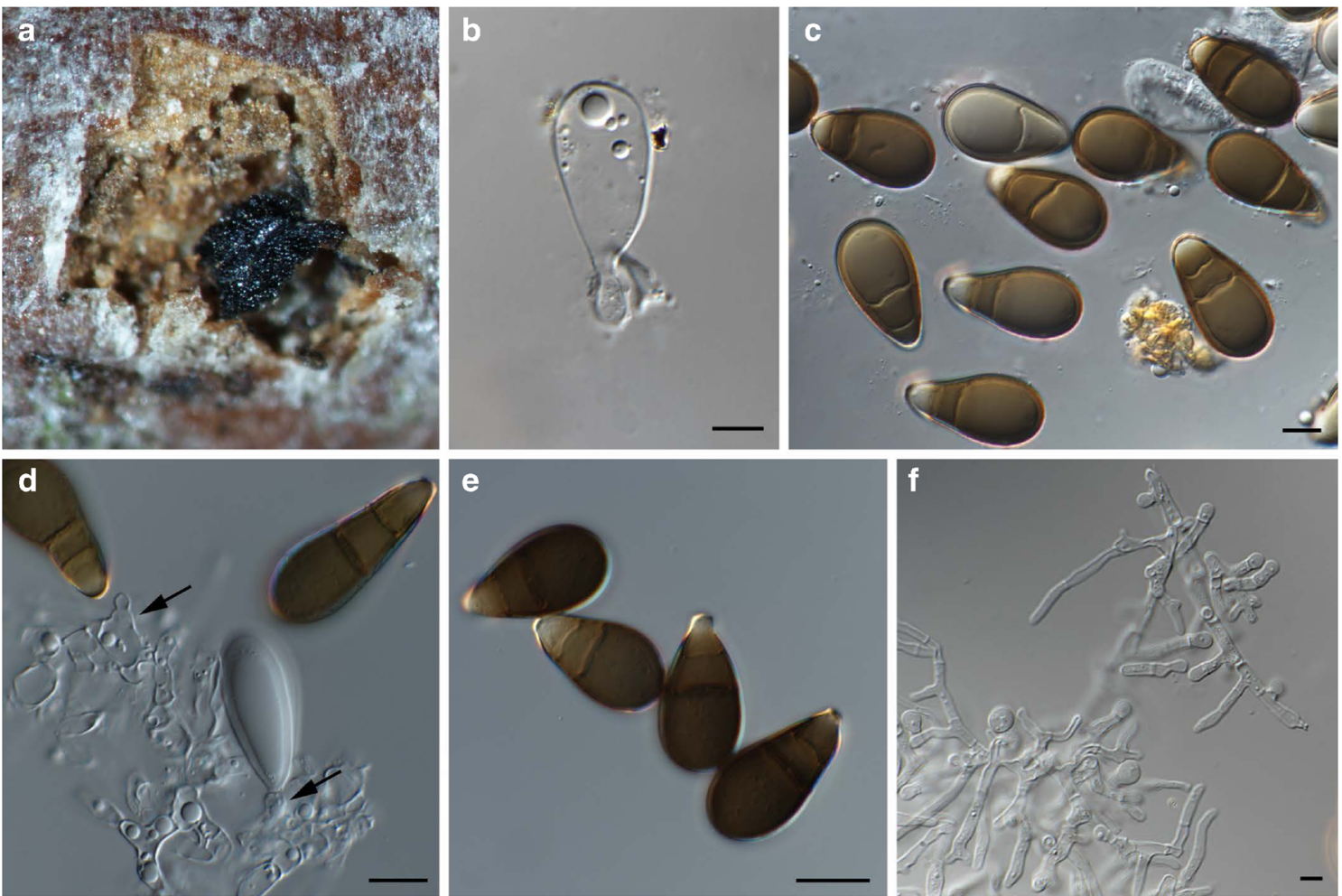

Fig. 8 Neohendersonia kickxii (CBS 112403). a Conidioma on Fagus sylvatica. b Conidiogenous cell in vivo. c Conidia in vivo showing the paler basal cell. d Conidiogenous cells in vitro (arrows). e Conidia

in vitro. f Second kind of conidia growing directly from the hyphae. Scale bars: $\mathbf{b}-\mathbf{e}=10 \mu \mathrm{m}, \mathbf{f}=5 \mu \mathrm{m}$

sylvatica in Belgium. Sutton and Pollack (1974) subsequently combined Stilbospora kickxii into Neohendersonia, and $N$. kickxii was proposed as the type species, being the older name. After the inclusion of $N$. congoensis, the generic concept was expanded to include species with euseptate conidia (Sutton 1975). Recently, a third species, N. fagi, has been described from the same source in Italy (Wijayawardene et al. 2016). Currently, from the three species accepted in the genus, only $N$. kickxii has living type material, and, therefore, we cannot elucidate the monophyly of the genus and the species boundaries. However, the three species can be morphologically distinguished by the presence of euseptate conidia in $N$. congoensis and the size of the distoseptate conidia in $N$. fagi $(30-48 \times 10-15 \mu \mathrm{m})$ and N. kickxii $(21-45.5 \times 12.5-20 \mu \mathrm{m})$ (Sutton 1975, 1980; Wijayawardene et al. 2016).

From the material examined here, the culture CPC 24865 was found to be phylogenetically distinct from the other isolates of $N$. kickxii and it could represent a different taxon. However, we prefer to not assign a name to this culture yet, since we did not find sufficient morphological characteristics to propose it as a different species.

Neohendersonia kickxii has been reported as a specific endophyte of beech twigs in Europe (Danti et al. 2002; Sieber 2007) and from beech bark in North American forests (Griesmer-Zakhar 2013), while N. congoensis and N. fagi have been described on stems of Aloe or Agave in Congo and branch of Fagus in Italy, respectively.

Authors: A. Giraldo, R.K. Schumacher and P.W. Crous.

Spumatoria Massee and E.S. Salmon, Ann. Bot. Lond. 15: 350 (1901).

Classification: Ophiostomataceae, Ophiostomatales, Sordariomycetes.

Current generic circumscription: Saprobic, coprophilous. Ascomata perithecial, single, gregarious, immersed, erumpent, loculus globose with one or seldom two necks per perithecium. Ascomatal neck centrally, terete, apically paler and conspicuously long fimbriate, basally dark brown to black, felty, textura prismatica. Peridium dark brown to black, slightly hard, rough, basally with red brown hyphae, textura angularis. Paraphyses longer than the asci. Asci 8-spored, clavate, apically rounded and with an ocular chamber, pedicel mostly short and not furcate, thick-walled, bitunicate. Ascospores obliquely biseriate, overlapped, 2(-3)-celled, clavate, straight, hyaline, thin-walled, smooth, coarsely guttulate, septa smooth and thin-walled. Asexual morph sporothrix-like (in culture). Conidiophores more or less differentiated, unbranched, cylindrical. Conidiogenous cells polyblastic, sympodial, terminal, denticulate. Conidia solitary, dacrioid, hyaline. Blastoconidia growing directly from undifferentiated hyphae, lateral, globose to subglobose. 

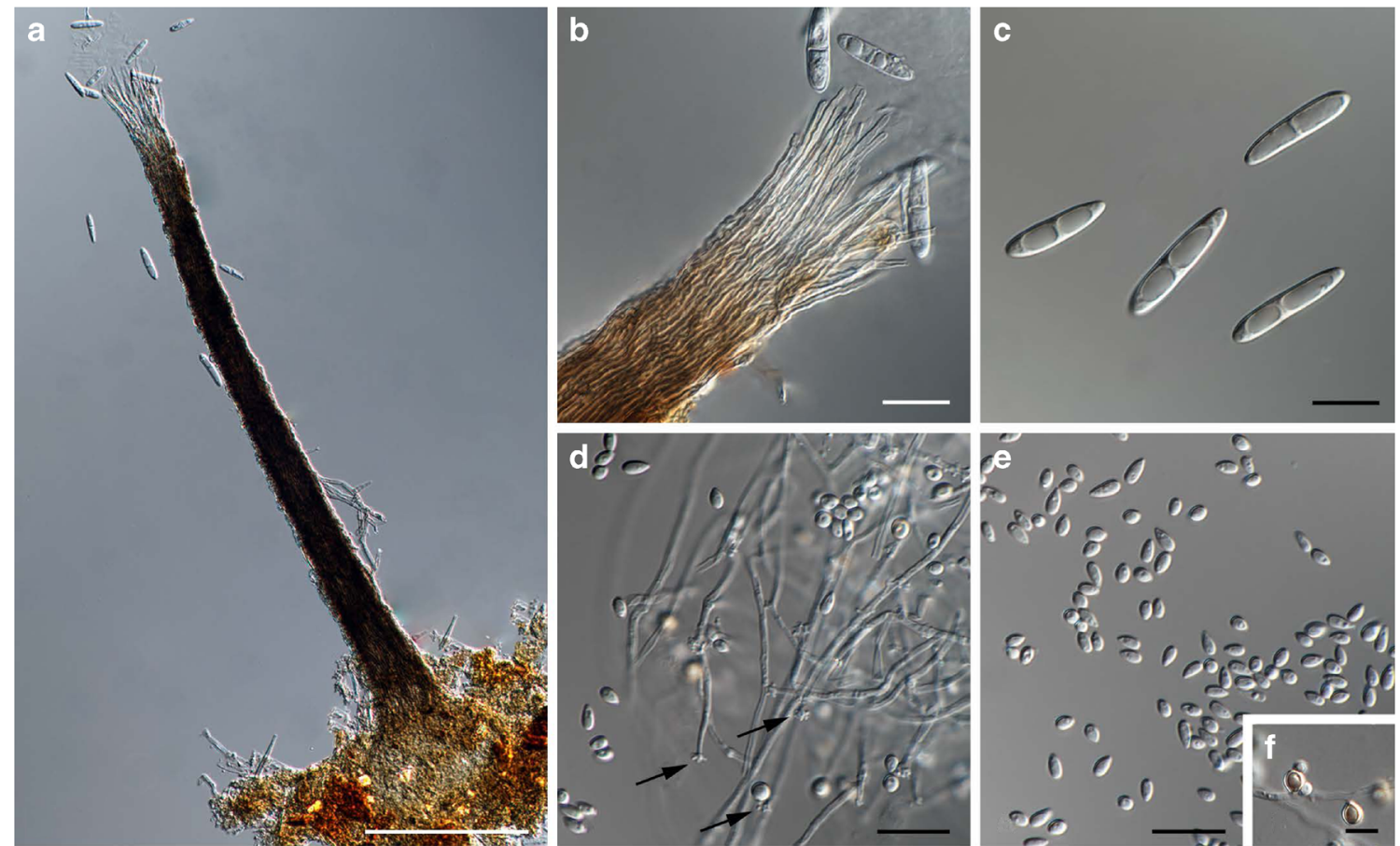

Fig. 9 Spumatoria longicollis (CBS 141464). a Ascoma. b Ostiolar hyphae. c Ascospores. d Conidiogenous cells (arrows denote the denticles). e Conidia. f Blastoconidia. Scale bars: $\mathbf{a}=100 \mu \mathrm{m}$, all others $=10 \mu \mathrm{m}$

Type species: Spumatoria longicollis Massee \& E.S. Salmon 1901.

Spumatoria longicollis Massee and E.S. Salmon, Ann. Bot. Lond. 15: 351 (1901). Fig. 9

MycoBank: MB 171713

Description: Ascomata single, gregarious, immersed, erumpent, loculus globose with one or seldom two necks per perithecium, up to $500 \mu \mathrm{m}$ long $\times 39-60 \mu \mathrm{m}$ wide. Ascomatal neck central, terete, apically paler and conspicuously long fimbriate, basally dark brown to black, felty, textura prismatica, up to $430 \mu \mathrm{m}$ long $\times 28-30 \mu \mathrm{m}$ wide. Peridium dark brown to black, slightly hard, rough, basally with red brown hyphae, textura angularis. Paraphyses longer than the asci. Asci dehiscent, 8-spored, clavate, apically rounded and with an ocular chamber, pedicel mostly short and not furcate, thick-walled, bitunicate. Ascospores obliquely biseriate, overlapped, 2(-3)-celled, clavate, straight, hyaline, thin-walled, smooth, coarsely guttulate, septa smooth and thin-walled, (17) 18-23(26) × 4-7.5 $\mu \mathrm{m}$. Asexual morph sporothrix-like (in culture). Conidiophores poorly differentiated, unbranched, cylindrical, up to $30 \mu \mathrm{m}$ long. Conidiogenous cells polyblastic, sympodial, terminal, denticulate. Conidia dacrioid, hyaline, smooth- and thin-walled, 3-4.5 $\times 1.5-$ $2 \mu \mathrm{m}$. Blastoconidia growing directly from undifferentiated hyphae, lateral, globose to subglobose, smooth- and thickwalled, light brown, 3-4 × 2-4 $\mu \mathrm{m}$ wide.

Culture characteristics: Colonies on OA attaining 13$20 \mathrm{~mm}$ diam. after 1 week at $25{ }^{\circ} \mathrm{C}$, flat, scarce aerial mycelium, dark brown. On MEA flat, creamy with scarce aerial mycelium, dirty white turning dark brown with age.

Specimens examined: England, Essex, Epping Forest, horse dung, G.E. Massee \& E.S. Salmon [Massee G.E and E.S. Salmon, Ann. Bot. Lond. 15, Fig. 27] (Lectotype designed here, MycoBank MBT373089). Netherlands, near Oostvoorne, dune grassland, on cow (Galloway) dung, 26 Jan. 2016, coll. J. van der Lee, det. R.K. Schumacher, iso. A. Giraldo (epitype designated here, CBS H-22665, MycoBank MBT373090; culture ex-epitype CBS $141464=$ CPC 30521).

Notes: As far as we know, this is the first report of this fungus after its original description. The sexual morph was only observed in natural substrata; many attempts to obtain this morph in culture resulted only in the sporothrix-like asexual morph. Several macroscopic and microscopic pictures were observed to corroborate the identity from the specimen. In the original protologue, Massee and Salmon (1901) mentioned cylindrical asci, 110-113 $\times 13-15 \mu \mathrm{m}$, versus narrow clavate in the illustration, and 2-celled, ellipsoidal ('oblongis utrinque rotundatis') spores, $15-19 \times 5 \mu \mathrm{m}$. Unfortunately, due to the dehiscent nature of the asci and the scarce material available, these structures were not observed in this study. The authors refer the perithecia at the conidium-bearing stage to the genus Rhynchophoma, a similar genus described from the wood of Tilia ulmifolia (Karsten 1884). However, the type of this fungus is apparently lost and, according to De Beer et al. (2013), this genus does not belong to either Ophiostomatales or Microascales. 
Among the coprophilous fungi, Kathistes is one of the genera morphologically similar to Spumatoria in having transversely septate ascospores and perithecia with long and dark necks, but can be differentiated by its narrower ascospores, particular sporidiomata and absence of paraphyses (Malloch and Blackwell 1990). Based on their morphological similarities and common habit, they were placed together with Klasterskya in the Kathistaceae within Ophiostomatales (Hawksworth et al. 1995; Kirk et al. 2008). However, the analysis of the SSU region showed the affinity of this family to be with the Dothideomycetes rather than the Ophiostomatales (Blackwell and Spatafora 1994); consequently, Klasterskya and Spumatoria were excluded from the latter order based on the morphological characters as reported in the original description (De Beer et al. 2013). It is important to mention that, from the approximately 300 genera currently included in the Ophiostomatales, Spumatoria is the only genus showing septate ascospores. However, our results of the molecular data, which include LSU (Fig. 4), ITS and $\beta$ tubulin (data not shown) loci, demonstrate the inclusion of the latter genus within the Ophiostomatales. Based on phylogenetic placement, Spumatoria could be considered a synonym of the older name Sporothrix (Hektoen and Perkins 1900). Although $S$. longicollis also have a sporothrix-like asexual state, it differs from other Sporothrix spp. based on septate ascospores, light coloured ascomata and dung-inhabiting biology. We, thus, suggest that further study including sequences of multiple gene regions and more taxa is needed in order to elucidate its relation with the type species of Sporothrix, S. schenckii and other species in the genus.

Authors: RK Schumacher, A Giraldo and PW Crous

Acknowledgements Alejandra Giraldo is grateful for the financial support received from the postdoctoral fellowship programme from the University of Pretoria. MG-N and EL thank the curators of K and CFMR herbaria for their kind permission to publish photographs from the loaned material, and acknowledge the support received from the Department of Ecology, University of Kassel.

Open Access This article is distributed under the terms of the Creative Commons Attribution 4.0 International License (http:// creativecommons.org/licenses/by/4.0/), which permits unrestricted use, distribution, and reproduction in any medium, provided you give appropriate credit to the original author(s) and the source, provide a link to the Creative Commons license, and indicate if changes were made.

\section{References}

Ahmed SA, van de Sande WWJ, Stevens DA et al (2014) Revision of agents of black-grain eumycetoma in the order Pleosporales. Persoonia 33:141-154

Aveskamp MM, de Gruyter J, Woudenberg JH, Verkley GJ, Crous PW (2010) Highlights of the Didymellaceae: a polyphasic approach to characterise Phoma and related pleosporalean genera. Stud Mycol 65:1-60
Batzer JC, Arias MM, Harrington TC et al (2008) Four species of Zygophiala (Schizothyriaceae, Capnodiales) are associated with the sooty blotch and flyspeck complex on apple. Mycologia 100: 246-258

Berkeley MJ, Broome CE (1875) Enumeration of the fungi of Ceylon. Part II. Bot J Linn Soc 14:29-141

Blackwell M, Spatafora JW (1994) Molecular data sets and broad taxon sampling in detecting morphological convergence. In: Hawksworth DL (ed) First international workshop on Ascomycetes systematics. Plenum Press, New York, pp 243-248

Boehm EW, Schoch CL, Spatafora JW (2009) On the evolution of the Hysteriaceae and Mytilinidiaceae (Pleosporomycetidae, Dothideomycetes, Ascomycota) using four nuclear genes. Mycol Res 113:461-479

Campbell J, Ferrer A, Raja HA, Sivichai S, Shearer CA (2007) Phylogenetic relationships among taxa in the Jahnulales inferred from $18 \mathrm{~S}$ and $28 \mathrm{~S}$ nuclear ribosomal DNA sequences. Can J Bot 85:873-882

Castlebury LA, Rossman AY, Jaklitsch WJ, Vasilyeva LN (2002) A preliminary overview of the Diaporthales based on large subunit nuclear ribosomal DNA sequences. Mycologia 94:1017-1031

Cheewangkoon R, Crous PW, Hyde KD, Groenewald JZ, To-anan C (2008) Species of Mycosphaerella and related anamorphs on Eucalyptus leaves from Thailand. Persoonia 21:77-91

Cheewangkoon R, Groenewald JZ, Summerell BA et al (2009) Myrtaceae, a cache of fungal biodiversity. Persoonia 23:55-85

Cheewangkoon R, Groenewald JZ, Hyde KD, To-anun C, Crous PW (2012) Chocolate spot disease of Eucalyptus. Mycol Prog 11:61-69

Chen Q, Jiang JR, Zhang GZ, Cai L, Crous PW (2015) Resolving the Phoma enigma. Stud Mycol 82:137-217

Crous PW, Groenewald JZ (2011) Why everlastings don't last. Persoonia 26:70-84

Crous PW, Groenewald JZ (2013) A phylogenetic re-evaluation of Arthrinium. IMA Fungus 4:133-154

Crous PW, Wingfield MJ, Park RF (1991) Mycosphaerella nubilosa, a synonym of $M$. molleriana. Mycol Res 95:628-632

Crous PW, Gams W, Stalpers JA, Robert V, Stegehuis G (2004) MycoBank: an online initiative to launch mycology into the 21st century. Stud Mycol 50:19-22

Crous PW, Groenewald JZ, Wingfield MJ (2006a) Heteroconium eucalypti. Fungal Planet no. 10

Crous PW, Slippers B, Wingfield MJ et al (2006b) Phylogenetic lineages in the Botryosphaeriaceae. Stud Mycol 55:235-253

Crous PW, Braun U, Groenewald JZ (2007a) Mycosphaerella is polyphyletic. Stud Mycol 58:1-32

Crous PW, Mohammed C, Glen M, Verkley GJM, Groenewald JZ (2007b) Eucalyptus microfungi known from culture. 3. Eucasphaeria and Sympoventuria genera nova, and new species of Furcaspora, Harknessia, Heteroconium and Phacidiella. Fungal Divers 25:19-36

Crous PW, Schoch CL, Hyde KD et al (2009a) Phylogenetic lineages in the Capnodiales. Stud Mycol 64:17-47

Crous PW, Summerell BA, Carnegie AJ et al (2009b) Unravelling Mycosphaerella: do you believe in genera? Persoonia 23:99-118

Crous PW, Verkley GJM, Groenewald JZ, Samson RA (2009c) Fungal biodiversity. CBS Laboratory Manual Series no.1. CBS-KNAW Fungal Biodiversity Centre, Utrecht, the Netherlands

Crous PW, Groenewald JZ, Shivas RG et al (2011) Fungal planet description sheets: 69-91. Persoonia 26:108-156

Crous PW, Summerell BA, Shivas RG et al (2012) Fungal planet description sheets: 107-127. Persoonia 28:138-182

Crous PW, Wingfield MJ, Guarro J et al (2013) Fungal planet description sheets: 154-213. Higher order classification of taxonomic novelties. Persoonia 31:186-296 
Crous PW, Giraldo A, Hawksworth DL et al (2014a) The Genera of fungi: fixing the application of type species of generic names. IMA Fungus 5:141-160

Crous PW, Shivas RG, Quaedvlieg W et al (2014b) Fungal planet description sheets: 214-280. Persoonia 32:184-306

Crous PW, Wingfield MJ, Schumacher RK et al (2014c) Fungal planet description sheets: 281-319. Persoonia 33:212-289

Crous PW, Carris LM, Giraldo A et al (2015a) The Genera of Fungifixing the application of the type species of generic names $-\mathrm{G} 2$ : Allantophomopsis, Latorua, Macrodiplodiopsis, Macrohilum, Milospium, Protostegia, Pyricularia, Robillarda, Rotula, Septoriella, Torula, and Wojnowicia. IMA Fungus 6:163-198

Crous PW, Wingfield MJ, Guarro J et al (2015b) Fungal planet description sheets: 320-370. Persoonia 34:167-266

Cunningham GH (1956) Thelephoraceae of New Zealand. Part IX. The genus Stereum. Part X. The genera Cytidia and Aleurocystis. Part XI. The genus Aleurodiscus. Trans Roy Soc NZ 84:201-268

Dai DQ, Bahkali AH, Li WJ, Bhat DJ, Zhao RL, Hyde KD (2015) Bambusicola loculata sp. nov. (Bambusicolaceae) from bamboo. Phytotaxa 213:122-130

Danti R, Sieber TN, Sanguineti G (2002) Endophytic mycobiota in bark of European beech (Fagus sylvatica) in the Apennines. Mycol Res 106:1343-1348

De Beer ZW, Seifert KA, Wingfield MJ (2013) The ophiostomatoid fungi: their dual position in the Sordariomycetes. In: Seifert KA, de Beer ZW, Wingfield MJ (eds) The Ophiostomatoid fungi: expanding frontiers. CBS Biodiversity Series no. 12. CBS-KNAW Fungal Biodiversity Centre, Utrecht, the Netherlands, pp 1-19

De Beer ZW, Duong TA, Wingfield MJ (2016) The divorce of Sporothrix and Ophiostoma: solution to a problematic relationship. Stud Mycol 83:165-191

de Gruyter J, Aveskamp MM, Woudenberg JH, Verkley GJ, Groenewald JZ, Crous PW (2009) Molecular phylogeny of Phoma and allied anamorph genera: towards a reclassification of the Phoma complex. Mycol Res 113:508-519

de Gruyter J, Woudenberg JH, Aveskamp MM, Verkley GJ, Groenewald JZ, Crous PW (2010) Systematic reappraisal of species in Phoma section Paraphoma, Pyrenochaeta and Pleurophoma. Mycologia 102:1066-1081

de Gruyter J, Woudenberg JH, Aveskamp MM, Verkley GJ, Groenewald JZ, Crous PW (2013) Redisposition of phoma-like anamorphs in Pleosporales. Stud Mycol 75:1-36

de Hoog GS, Gerrits van den Ende AHG (1998) Molecular diagnostics of clinical strains of filamentous Basidiomycetes. Mycoses 41:183189

de Meyer EM, de Beer ZW, Summerbell RC et al (2008) Taxonomy and phylogeny of new wood- and soil-inhabiting Sporothrix species in the Ophiostoma stenoceras-Sporothrix schenckii complex. Mycologia 100:647-661

Griesmer-Zakhar RE (2013) Beech bark disease distribution and resistance in Michigan and fungal endophyte ecology of resistant and susceptible beech (Fagus grandifolia Ehrh.). Master's thesis, Michigan Technological University

Grove WB (1937) British stem- and leaf-fungi (Coelomycetes). Volume 2. Cambridge University Press, Cambridge

Guatimosim E, Firmino AL, Bezerra JL, Pereira OL, Barreto RW, Crous PW (2015) Towards a phylogenetic reappraisal of Parmulariaceae and Asterinaceae (Dothideomycetes). Persoonia 35:230-241

Hawksworth DL, Kirk PM, Sutton BC, Pegler DN (1995) Ainsworth \& Bisby's dictionary of the fungi, 8th edn. Commonwealth Agricultural Bureau International, Wallingford, Oxon, UK

Hektoen L, Perkins CF (1900) Refractory subcutaneous abscesses caused by Sporothrix schenckii. A new pathogenic fungus. J Exp Med 5: 77-89
Hernández-Restrepo M, Groenewald JZ, Crous PW (2016) Taxonomic and phylogenetic re-evaluation of Microdochium, Monographella and Idriella. Persoonia 36:57-82

Hirayama K, Tanaka K (2011) Taxonomic revision of Lophiostoma and Lophiotrema based on reevaluation of morphological characters and molecular analyses. Mycoscience 52:401-412

Hirayama K, Tanaka K, Raja HA, Miller AN, Shearer CA (2010) A molecular phylogenetic assessment of Massarina ingoldiana sensu lato. Mycologia 102:729-746

Hjortstam K (1989) Corticioid fungi described by M. J. Berkeley. Kew Bull 44:301-315

Hyde KD, Jones EBG, Liu J-K et al (2013) Families of Dothideomycetes. Fungal Divers 63:1-313

Jaklitsch WM, Gardiennet A, Voglmayr H (2016) Resolution of morphology-based taxonomic delusions: Acrocordiella, Basiseptospora, Blogiascospora, Clypeosphaeria, Hymenopleella, Lepteutypa, Pseudapiospora, Requienella, Seiridium and Strickeria. Persoonia 37:82-105

Jeewon R, Liew EC, Hyde KD (2002) Phylogenetic relationships of Pestalotiopsis and allied genera inferred from ribosomal DNA sequences and morphological characters. Mol Phylogenet Evol 25: 378-392

Kang JC, Hyde KD, Kong RYC (1999) Studies on the Amphisphaeriales I. The Clypeosphaeriaceae. Mycoscience 40:151-164

Karsten PA (1884) Fragmenta mycologica IX. Hedwigia 23:18-20

Kirk PM, Cannon PF, Minter DW, Stalpers JA (2008) Dictionary of the fungi, 10th edn. Commonwealth Agricultural Bureau International, Wallingford, Oxon, UK

Kirk PM, Stalpers JA, Braun U et al (2013) A without-prejudice list of generic names of fungi for protection under the International Code of Nomenclature for algae, fungi and plants. IMA Fungus 4:381443

Knapp DG, Kovács GM, Zajta E, Groenewald JZ, Crous PW (2015) Dark septate endophytic pleosporalean genera from semiarid areas. Persoonia 35:87-100

Lemke PA (1964) The genus Aleurodiscus (sensu lato) in North America. Can J Bot 42:723-768

Liu JK, Phookamsak R, Dai DQ et al (2014) Roussoellaceae, a new pleosporalean family to accommodate the genera Neoroussoella gen. nov., Roussoella and Roussoellopsis. Phytotaxa 181:1-33

Lumbsch HT, Schmitt I, Lindemuth R et al (2005) Performance of four ribosomal DNA regions to infer higher-level phylogenetic relationships of inoperculate euascomycetes (Leotiomyceta). Mol Phylogenet Evol 34:512-524

Maharachchikumbura SSN, Hyde KD, Jones EBG et al (2016) Families of Sordariomycetes. Fungal Divers 79:1-317

Malloch D, Blackwell M (1990) Kathistes, a new genus of pleomorphic Ascomycetes. Can J Bot 68:1712-1721

Massee GE, Salmon ES (1901) Researches on coprophilous fungi. Ann Bot 15:313-357

McTaggart AR, Grice KR, Shivas RG (2013) First report of Vialaea minutella in Australia, its association with mango branch dieback and systematic placement of Vialaea in the Xylariales. Aust Plant Dis Notes 8:63-66

Miller SL, Larsson E, Larsson KH, Verbeken A, Nuytinck J (2006) Perspectives in the new Russulales. Mycologia 98:960-970

Petrak F (1921) Mykologische Notizen. III. Annals Mycol 19:176-223

Quaedvlieg W, Groenewald JZ, de Jesús Yáñez-Morales M, Crous PW (2012) DNA barcoding of Mycosphaerella species of quarantine importance to Europe. Persoonia 29:101-115

Quaedvlieg W, Verkley GJ, Shin HD et al (2013) Sizing up Septoria. Stud Mycol 75:307-390

Quaedvlieg W, Binder M, Groenewald JZ et al (2014) Introducing the consolidated species concept to resolve species in the Teratosphaeriaceae. Persoonia 33:1-40 
Raja H, Schoch CL, Hustad V, Shearer C, Miller A (2011) Testing the phylogenetic utility of MCM7 in the Ascomycota. MycoKeys 1:63-94

Rayner RW (1970) A mycological colour chart. Commonwealth Mycological Institute, Kew

Robert V, Vu D, Amor ABH et al (2013) MycoBank gearing up for new horizons. IMA Fungus 4:371-379

Ryvarden L (1998) The genus Aleurocystis. Cryptogam Mycol 19:93-97

Ryvarden L (2010) Stereoid fungi of America. Syn Fung 28:1-206

Schoch CL, Kohlmeyer J, Volkmann-Kohlmeyer B, Tsui CK, Spatafora JW (2006a) The halotolerant fungus Glomerobolus gelineus is a member of the Ostropales. Mycol Res 110:257-263

Schoch CL, Shoemaker RA, Seifert KA, Hambleton S, Spatafora JW, Crous PW (2006b) A multigene phylogeny of the Dothideomycetes using four nuclear loci. Mycologia 98:1041-1052

Schoch CL, Crous PW, Groenewald JZ, Boehm EWA (2009a) A classwide phylogenetic assessment of Dothideomycetes. Stud Mycol 64: $1-15$

Schoch CL, Sung GH, López-Giráldez F et al (2009b) The Ascomycota tree of life: a phylum-wide phylogeny clarifies the origin and evolution of fundamental reproductive and ecological traits. Syst Biol 58:224-239

Schoch CL, Seifert KA, Huhndorf S et al (2012) Nuclear ribosomal internal transcribed spacer (ITS) region as a universal DNA barcode marker for Fungi. Proc Natl Acad Sci U S A 109:6241-6246

Senanayake IC, Maharachchikumbura SSN, Mortimer PE, Xu J, Bhat JD, Hyde KD (2014) Vialaeaceae; introducing a novel species Vialaea mangiferae. Sydowia 66:203-216

Senanayake IC, Maharachchikumbura SSN, Hyde KD et al (2015) Towards unraveling relationships in Xylariomycetidae (Sordariomycetes). Fungal Divers 73:73-144

Sieber TN (2007) Endophytic fungi in forest trees: are they mutualists? Fungal Biol Rev 21:75-89

Slippers B, Boissin E, Phillips AJ et al (2013) Phylogenetic lineages in the Botryosphaeriales: a systematic and evolutionary framework. Stud Mycol 76:31-49

Smith H, Wingfield MJ, Coutinho TA, Crous PW (1996) Sphaeropsis sapinea and Botryosphaeria dothidea endophytic in Pinus spp. and Eucalyptus spp. in South Africa. S Afr J Bot 62:86-88

Spatafora JW, Sung GH, Johnson D et al (2006) A five-gene phylogeny of Pezizomycotina. Mycologia 98:1018-1028

Suetrong S, Schoch CL, Spatafora JW et al (2009) Molecular systematics of the marine Dothideomycetes. Stud Mycol 64:155-173

Summerell BA, Groenewald JZ, Carnegie AJ, Summerbell RC, Crous PW (2006) Eucalyptus microfungi known from culture. 2. Alysidiella, Fusculina and Phlogicylindrium genera nova, with notes on some other poorly known taxa. Fungal Divers 23:323-350

Sutton BC (1975) Coelomycetes. V. Coryneum. Mycol Pap 138:1-224

Sutton BC (1980) The Coelomycetes: fungi imperfecti with pycnidia, acervuli, and stromata. Commonwealth Mycological Institute, Kew

Sutton BC, Pollack FG (1974) Microfungi on Cercocarpus. Mycopathol Mycol Appl 52:331-351
Swart HJ (1981) Australian leaf-inhabiting fungi: XI. Phyllachora eucalypti. Trans Br Mycol Soc 76:89-95

Swart HJ (1988) Australian leaf-inhabiting fungi. XXVI. Some noteworthy Coelomycetes on Eucalyptus. Trans Br Mycol Soc 90:279-291

Tamura K, Stecher G, Peterson D, Filipski A, Kumar S (2013) MEGA6: molecular evolutionary genetics analysis version 6.0. Mol Biol Evol 30:2725-2729

Tanaka K, Hirayama K, Yonezawa H et al (2015) Revision of the Massarineae (Pleosporales, Dothideomycetes). Stud Mycol 82:75-136

Tang AM, Jeewon R, Hyde KD (2007) Phylogenetic utility of protein (RPB2, beta-tubulin) and ribosomal (LSU, SSU) gene sequences in the systematics of Sordariomycetes (Ascomycota, Fungi). Antonie Van Leeuwenhoek 91:327-349

Tsui CK, Berbee ML (2006) Phylogenetic relationships and convergence of helicosporous fungi inferred from ribosomal DNA sequences. Mol Phylogenet Evol 39:587-597

van der Linde JA, Six DL, de Beer WZ, Wingfield MJ, Roux J (2016) Novel ophiostomatalean fungi from galleries of Cyrtogenius africus (Scolytinae) infesting dying Euphorbia ingens. Antonie Van Leeuwenhoek 109:589-601

Verkley GJM, Dukik K, Renfurm R, Göker M, Stielow JB (2014) Novel genera and species of coniothyrium-like fungi in Montagnulaceae (Ascomycota). Persoonia 32:25-51

Vilgalys R, Hester M (1990) Rapid genetic identification and mapping of enzymatically amplified ribosomal DNA from several Cryptococcus species. J Bacteriol 172:4238-4246

Wanasinghe DN, Jones EBG, Camporesi E et al (2014) An exciting novel member of Lentitheciaceae in Italy from Clematis vitalba. Cryptogam Mycol 35:323-337

White TJ, Bruns T, Lee J, Taylor SB (1990) Amplification and direct sequencing of fungal ribosomal RNA genes for phylogenetics. In: Innis MA, Gelfand DH, Sninsky JJ, White TJ (eds) PCR protocols: a guide to methods and applications. Academic Press, San Diego, pp 315-322

Wijayawardene NN, Hyde KD, Wanasinghe DN et al (2016) Taxonomy and phylogeny of dematiaceous coelomycetes. Fungal Divers 77:1316

Winton LM, Stone JK, Hansen EM, Shoemaker RA (2007) The systematic position of Phaeocryptopus gaeumannii. Mycologia 99:240 252

Zhang YI, Fournier J, Pointing SB, Hyde KD (2008) Are Melanomma pulvis-pyrius and Trematosphaeria pertusa congeneric? Fungal Divers 33:47-60

Zhang Y, Schoch CL, Fournier J et al (2009a) Multi-locus phylogeny of Pleosporales: a taxonomic, ecological and evolutionary re-evaluation. Stud Mycol 64:85-102

Zhang Y, Wang HK, Fournier J et al (2009b) Towards a phylogenetic clarification of Lophiostoma/Massarina and morphologically similar genera in the Pleosporales. Fungal Divers 38:225-251

Zipfel RD, de Beer ZW, Jacobs K, Wingfield BD, Wingfield MJ (2006) Multi-gene phylogenies define Ceratocystiopsis and Grosmannia distinct from Ophiostoma. Stud Mycol 55:75-97 